\title{
Vibrations of Flat-End Cutter Entering Workpiece Process: Modeling, Simulations, and Experiments
}

\author{
Ming Luo (i) and Qi Yao \\ Key Laboratory of Contemporary Design and Integrated Manufacturing Technology, Ministry of Education, \\ Northwestern Polytechnical University, Xi'an 710072, China \\ Correspondence should be addressed to Ming Luo; luoming@nwpu.edu.cn
}

Received 1 August 2018; Accepted 5 November 2018; Published 9 December 2018

Academic Editor: Xavier Chiementin

Copyright ( 2018 Ming Luo and Qi Yao. This is an open access article distributed under the Creative Commons Attribution License, which permits unrestricted use, distribution, and reproduction in any medium, provided the original work is properly cited.

During all the machining process, the milling cutter has to enter the workpiece either from the boundary or from the machined/unmachined surface, due to the change of machining sequence/cutter or the variation of cutting depth. Unlike the stable cutting process, the contact between cutter and machined workpiece changes significantly in the entering process, resulting in vibration and leaving marks on the machined surface. Aiming at in-depth understanding the mechanism of this phenomenon, this paper presents a novel time-domain simulation model to predict the dynamic response of the cutter during the entering process. Two typical entering conditions, including entering from the workpiece boundary and from the machined surface along the cycle path, are modeled based on the dynamic cutting force calculation by considering dynamic undeformed chip thickness created by consequential teeth engagement. Then, it is synthesized with the time-varying immersion angle and exit angle of cutter teeth in the entering process to simulate the dynamic cutting forces and cutter vibrations. To validate the developed model, eight conditions in boundary entering and six conditions in cycle path entering are carried out by comparing the collected data and the predicted results. Results show that the developed model could precisely predict the dynamic cutting forces and cutter vibration, especially the forces and displacements under the varied cutter-workpiece contact.

\section{Introduction}

As a long-developed traditional manufacturing process, machining is still significant in the contemporary manufacturing industry, including aerospace and aviation industry [1], for its high production quality, extensive application field, and high efficiency. In the machining process, surface roughness, which is one significant aspect of surface integrity $[2,3]$, is affected by cutter-workpiece relative movement, static deformation, dynamic properties [4], and tool wear [5]. The deformation and dynamic vibration caused by the low-stiffness of the cutters and the workpieces could leave serious vibration marks on the machined surface, leading to damage to the surface integrity for high value-added parts [6], such as the aeroengine blisk or casing parts. In the practical toolpath planning stage, the repeated cutter entering and exiting workpieces are inevitable. Basically, there are two types of cutter entering conditions: the cutter entering from the workpiece boundaries and entering from the machined/unmachined workpiece surfaces. In the cutter entering process, the engagement between the cutter and the workpiece varies dramatically. Unstable cutterworkpiece contact should take major responsibility for this harmful effect for the unstable contact that usually causes unstable vibration. Among previous investigations in machining dynamics and cutting force predictions [7], studies considering the entering of the cutter are limited, and there is a big research gap in addressing the phenomenon of the cutter entering workpiece process.

Vibration is one of the most common phenomena in the machining process, which is caused by the low stiffness of the cutter-holder system or the flexible workpieces [8]. Because of its bad effects on surface integrity, tool life, and productivity, the formation mechanism, stability boundary prediction [9], monitoring [10], and suppression methods of machining vibration [11] have been discussed for a long time. On revealing the mechanism, Taylor [12] made important progress by identifying the machining vibration as a regenerative 
vibration system. Furthermore, by applying stability theories, Altintas and Budak [13] proposed analytical solutions of stability boundary. Then, Insperger and Stépán [14] established a time-domain semidiscretization method via using Floquet theory, which is applicable in situations where analytical solutions do not exist. On this foundation, research on improving calculation efficiency [15], solving multiaxis stability problem [16] and synthesizing ploughing effect into stability prediction [17], was then carried out. Making the models more realistic, Sun and Jiang [18] extended the stability prediction into dual-vibration systems where both cutter and workpiece are flexible with the cutting force-induced deformation considered. In conclusion, the proposed machining vibration analysis and prediction methods have covered a wide range of potential factors influencing machining vibration. However, these works prefer the stability prediction of the normal machining process [19], ignoring the influence of cutter vibration in the entering process.

In modeling of the machining process, the time-domain modeling method that predicts the dynamic response of the machining system is a significant field. One typical approach is calculating the load on the cutter with geometric methods. For instance, Zhu et al. [20] tried to calculate the contact zone by using the cutter envelope and local geometry of workpiece. Some other works concentrate on the efficient cutter-workpiece engagements determination based on the discrete general cutter [21]. Other factors, such as cutter runout [22] and multiaxis cutter movement, are also considered by some researchers. Except calculating the contact zone, geometric methods are also used for load calculation with given cutter path and cutting parameter [23]. Even though these studies are successful in determining the quasistatic machining load, the vibration of cutters and workpieces is ignored. To compensate the shortages of this type of modeling method, some other works emphasized on synthesizing physical phenomena, mainly vibrations, into modeling process by considering dynamic load caused by system vibration [24]. For better load calculation, a real-time updated machined surface that is formed by cutter motions was also used in the modeling [25]. Following this basic method of considering system vibration, the flexibility of workpiece has also been modeled and synthesized into model [26], which is a significant progress in this area. These studies provide direct references for the modeling of cutter entering workpiece, especially the papers emphasizing dynamic properties of the machining system.

Thus, on reviewing current studies of machining vibration, it appears to be limited/scarce reports on modeling and analysis on cutter entering of workpiece process so that the entering process can be better controlled or optimized. This not only limits the deeper understanding of the phenomena occurring at the cutter entering process in the milling operations but also reduces the possibility to take actions during the process if malfunctions occur (e.g. vibration and overcut). Therefore, modeling and analysis of the cutter entering workpiece process is required and could be the further step of machining process control.

In this paper, to address the research gap of modeling of cutter entering workpiece process, a novel modeling method based on the dynamic entry angle and exit angle is proposed. Two typical cutter entering conditions are studied, including entering from the workpiece boundary and from the machined surface along the cycle path. In Section 2, a dynamic cutting force model combined with dynamic undeformed chip thickness is developed. Then, in Section 3, the variation of tool-workpiece contact under two different conditions is discussed and modeled, respectively. By using dynamic entry angle $\phi_{\mathrm{dst}}(t)$ and dynamic exit angle $\phi_{\mathrm{dex}}(t)$, a simplified prediction program is constructed for the two cases. Finally, cutting tests are carried out to validate the designed model in Section 4 with conclusions in Section 5.

\section{Analytical Cutting Force Model considering Cutter Vibration}

When a rotating milling cutter is entering the workpiece, intermittent excitation of cutter teeth on the workpiece is easy to induce vibrations of the cutter. Vibrations will change the immersion angles during the milling process, thus changing the cutting forces. To this end, a cutting force model considering cutter vibrations is developed in this section, and it is the basis for the cutter entering process analysis. To calculate the cutting forces in the milling process, discretize the cutter into multiple disks along the axis direction, and the total forces on the cutter will be the sum of forces on all disks. The thickness of each disk is $d z$ as shown in Figure 1.

While one tooth is engaging workpiece, cutting forces acting on one disk are the tangential force $F_{\mathrm{t}}$, radial force $F_{\mathrm{r}}$, and axial force $F_{\mathrm{a}}$, and they are calculated as follows [9]:

$$
\left\{\begin{array}{l}
F_{\mathrm{t}, i, j}(t)=K_{\mathrm{tc}} h(t) d z+K_{\mathrm{te}} d z, \\
F_{\mathrm{r}, i, j}(t)=K_{\mathrm{rc}} h(t) d z+K_{\mathrm{re}} d z, \\
F_{\mathrm{a}, i, j}(t)=K_{\mathrm{ac}} h(t) d z+K_{\mathrm{ae}} d z,
\end{array}\right.
$$

where $K_{\mathrm{tc}}, K_{\mathrm{rc}}$, and $K_{\mathrm{ac}}$ are the shearing coefficients and $K_{\mathrm{te}}$, $K_{\mathrm{re}}$, and $K_{\mathrm{ae}}$, are the edge coefficients. The undeformed chip thickness (UCT) $h(t)$ is approximated by a function of the position angle $\left(\psi_{i, j}\right)$ of a disk $(j)$ on a tooth $(i)$ and fed per tooth $f_{z}$ as

$$
h(t)=f_{z} \sin \left(\psi_{i, j}(t)\right) .
$$

Let $\phi_{\mathrm{p}}$ be the pitch angle of the teeth, then $\psi_{i, j}(t)$ could be expressed as

$$
\psi_{i, j}(t)=\phi(t)-(i-1) \phi_{\mathrm{p}}-(j-1) k_{\beta} d z,
$$

where $k_{\beta}=(2 \tan \beta) / D, D$ is the cutter diameter, $\beta$ is the cutter helix angle, and $\phi(t)$ is the rotation angle of the cutter.

These three force components' directions and amplitude change with the rotation of the cutter. To transform forces into a workpiece coordinate system (WCS), the following transformation is constructed:

$$
\left[\begin{array}{l}
F_{x, i, j}(t) \\
F_{y, i, j}(t) \\
F_{z, i, j}(t)
\end{array}\right]=\mathbf{T}(t)\left[\begin{array}{l}
F_{\mathrm{t}, i, j}(t) \\
F_{\mathrm{r}, i, j}(t) \\
F_{\mathrm{a}, i, h}(t)
\end{array}\right],
$$

where $\mathbf{T}(t)$ is the transform matrix: 

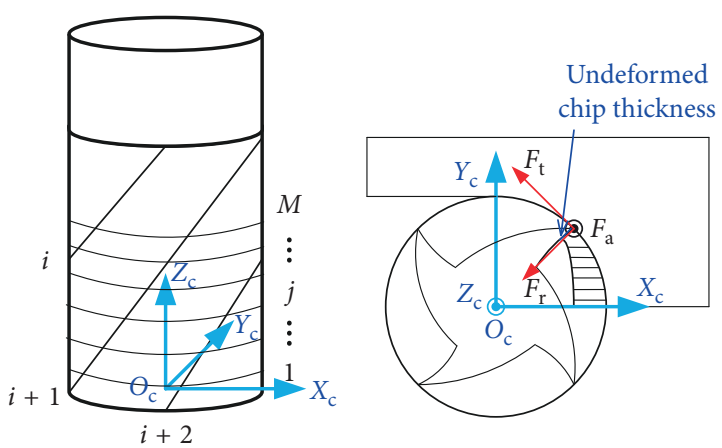

FIGURE 1: Discretization of cutter, forces imposed on one disk, and undeformed chip thickness on rake face.

$$
\mathbf{T}(t)=\left[\begin{array}{ccc}
-\cos \left(\psi_{i, j}(t)\right) & -\sin \left(\psi_{i, j}(t)\right) & 0 \\
\sin \left(\psi_{i, j}(t)\right) & -\cos \left(\psi_{i, j}(t)\right) & 0 \\
0 & 0 & 1
\end{array}\right] .
$$

By summing forces on all disks, the forces on the entire cutter can be expressed as

$$
\left[\begin{array}{l}
F_{x}(t) \\
F_{y}(t) \\
F_{z}(t)
\end{array}\right]=\sum_{i=1}^{N} \sum_{j=1}^{M}\left[\begin{array}{l}
F_{x, i, j}(t) \\
F_{y, i, j}(t) \\
F_{z, i, j}(t)
\end{array}\right] .
$$

The above cutting force model is used for conditions without vibrations. However, in the practical machining process, the cutter-spindle system is not ideally rigid and machining vibration exists. The vibration of the cutter caused by low stiffness of the spindle-holder-cutter system can damage the surface integrity of machined workpiece [27]. Since the stiffness in the axial direction is usually large, only cutter vibrations in the feed and cross-feed directions are considered in this study. In this way, the end of the cutter can be represented by a two-degree-of-freedom system, as shown in Figure 2. The vibration of this system can be described as

$$
\mathbf{M a}(t)+\mathbf{C v}(t)+\mathbf{K X}(t)=\mathbf{F}(t)
$$

where

$$
\begin{aligned}
\mathbf{M} & =\left[\begin{array}{cc}
m_{x} & 0 \\
0 & m_{y}
\end{array}\right], \\
\mathbf{C} & =\left[\begin{array}{ll}
c_{x} & 0 \\
0 & c_{y}
\end{array}\right], \\
\mathbf{K} & =\left[\begin{array}{ll}
k_{x} & 0 \\
0 & k_{y}
\end{array}\right], \\
\mathbf{a}(t) & =\left[\begin{array}{l}
a_{x}(t) \\
a_{y}(t)
\end{array}\right], \\
\mathbf{v}(t) & =\left[\begin{array}{l}
v_{x}(t) \\
v_{y}(t)
\end{array}\right], \\
\mathbf{X}(t) & =\left[\begin{array}{l}
x(t) \\
y(t)
\end{array}\right], \\
\mathbf{F}(t) & =\left[\begin{array}{l}
F_{x}(t) \\
F_{y}(t)
\end{array}\right] .
\end{aligned}
$$

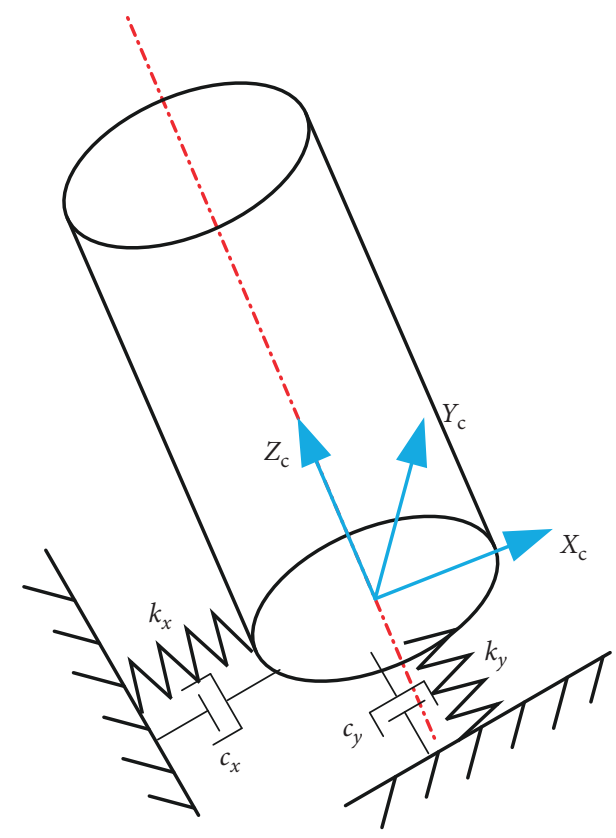

Figure 2: The two-degree-of-freedom vibration model of the cutter.

The stiffness parameters could be obtained through modal testing.

Cutter vibration changes the contact conditions between the cutter and the workpiece. In Figure 3, the machined surface free of vibration is represented by the black line. In this situation, the undeformed chip thickness could be approximated by a sinusoidal function. In the previous derivation, the UCT is expressed by Equation (2). When the cutter is vibrating, the dynamic displacements of the cutter in $x$ and $y$ directions change continuously. The integrated effect of cutter vibration and cycloid motion is that the tooth tips move around the original cycloids along wavy curves. Finally, the flute will leave wavy surfaces on the newly machined surface, as red curves shown in Figure 3.

Obviously, the UCT in machining progress is affected by the instantaneous displacement and the wavy surface left by the previous tooth that has engaged the workpiece. It is also nonnegligible that when the vibration reaches a magnitude that enables one or more than one tooth disengage workpiece, the load on next flute will be affected by the former tooth that has removed materials. And the position of this flute is the one that has smallest vibrational displacements ahead of the contemporary simulation point [28]. To take this situation into consideration, an additional feed item at $t$ is introduced and added to the ideal feed per tooth and expressed as

$$
\begin{aligned}
\mathbf{f}_{\mathrm{v}}(t)= & \mathbf{D}_{\mathrm{c}}(t)-\mathbf{D}_{\mathrm{p}}(t)=\left[\begin{array}{l}
x_{\mathrm{c}}(t) \\
y_{\mathrm{c}}(t)
\end{array}\right] \\
& -\left[\begin{array}{l}
\min \left\{x_{\mathrm{c}}(t-\Delta t), x_{\mathrm{c}}(t-2 \Delta t), \ldots, x_{\mathrm{c}}(t-N \Delta t)\right\} \\
\min \left\{y_{\mathrm{c}}(t-\Delta t), y_{\mathrm{c}}(t-2 \Delta t), \ldots, y_{\mathrm{c}}(t-N \Delta t)\right\}
\end{array}\right],
\end{aligned}
$$

where $\Delta t$ is the time for the cutter to rotate a pitch angle and $x_{\mathrm{c}}(t)$ and $y_{\mathrm{c}}(t)$ are the cutter displacements in the $x$ and $y$ 


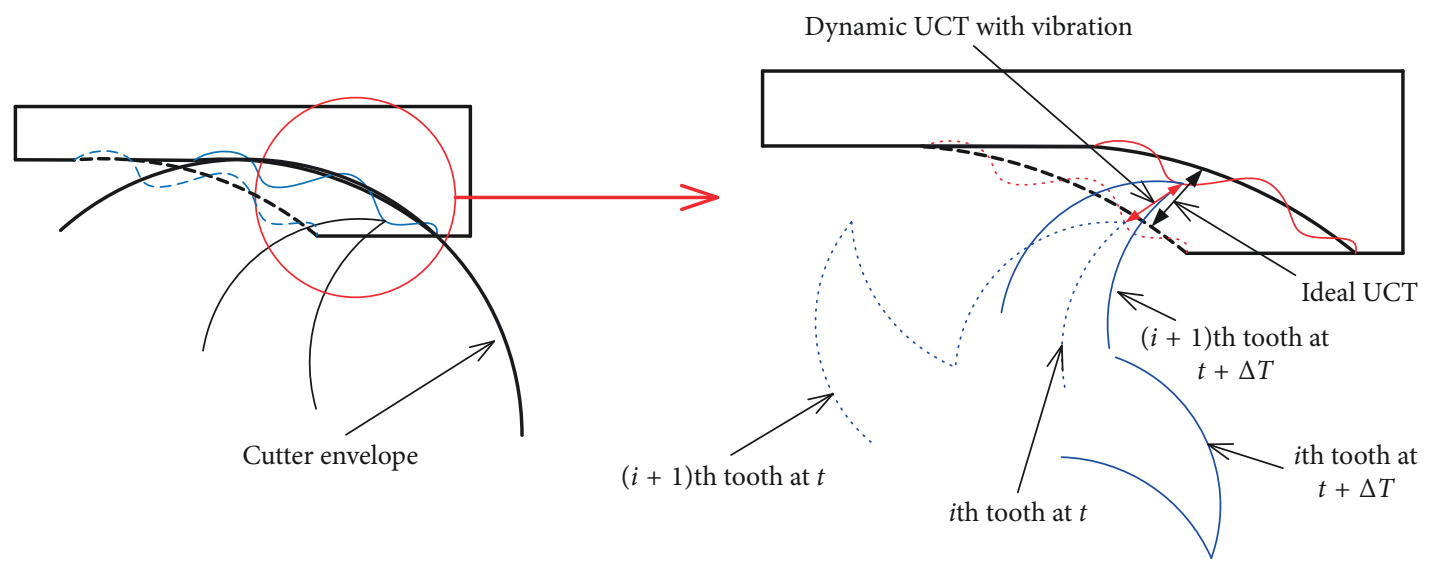

Figure 3: The influence of vibration on the undeformed chip thickness.

directions, respectively. By combining the addition feed with cutter rotation, the dynamic undeformed chip thickness can be derived as

$$
\begin{aligned}
H_{i, j}(t) & =h_{\mathrm{s}}\left(\psi_{i, j}(t)\right)+h_{\mathrm{d}}\left(\psi_{i, j}(t)\right) \\
& =f_{z} \sin \left(\psi_{i, j}(t)\right)+\left[\sin \left(\psi_{i, j}(t)\right) \cos \left(\psi_{i, j}(t)\right)\right] \mathbf{f}_{\mathrm{v}}(t) .
\end{aligned}
$$

Then, cutting forces acting on one individual disk are

$$
\left\{\begin{array}{l}
F_{\mathrm{t}, i, j}(t)=K_{\mathrm{tc}} H_{i, j}(t) d z+K_{\mathrm{te}} d z, \\
F_{\mathrm{r}, i, j}(t)=K_{\mathrm{rc}} H_{i, j}(t) d z+K_{\mathrm{re}} d z, \\
F_{\mathrm{a}, i, j}(t)=K_{\mathrm{ac}} H_{i, j}(t) d z+K_{\mathrm{ae}} d z .
\end{array}\right.
$$

Cutting forces transformed into the WCS are

$$
\left[\begin{array}{l}
F_{x, i, j}(t) \\
F_{y, i, j}(t) \\
F_{z, i, j}(t)
\end{array}\right]=\mathbf{T}_{i, j}(t)\left[\begin{array}{l}
F_{\mathrm{t}, i, j}(t) \\
F_{\mathrm{r}, i, j}(t) \\
F_{\mathrm{a}, i, j}(t)
\end{array}\right] .
$$

By summing forces on all disks, the forces acting on the whole cutter are expressed as

$$
\left[\begin{array}{l}
F_{x}(t) \\
F_{y}(t) \\
F_{z}(t)
\end{array}\right]=\sum_{i=1}^{N} \sum_{j=1}^{M}\left[\begin{array}{l}
F_{x, i, j}(t) \\
F_{y, i, j}(t) \\
F_{z, i, j}(t)
\end{array}\right] .
$$

With the above derivation, effects of cutter vibration on the cutting forces can be taken into consideration. However, for the nonlinear calculation of dynamic undeformed chip thickness and time-lag effect, the prediction program is relatively complex. To simulate the cutter entering workpiece process, the model should be synthesized with the variation of cutter-workpiece engagement, which will be discussed in the following section.

\section{Analytical Modeling of the Cutter Entering Workpiece}

In the practical machining process, there are two basic types of cutter entering cases. One is the cutter entering workpiece from the boundaries of workpieces, which is normally used in common tool paths. The other one is the cutter entering from the machined/unmachined surface of the workpiece, which is theoretically prohibited for vibration marks left by this process. Since the variations of cutter-workpiece contact in the two cases are totally different, the contact conditions will be analyzed separately and then combined with the cutting force model developed in Section 2.

3.1. Analytical Modeling of the Cutter Entering from Workpiece Boundary. In the milling process, a basic entering type for the cutter is to enter the workpiece along a straight line with the tool axis perpendicular to the workpiece surface, as shown in Figure 4. In the entering process, since the time period for the cutter entering workpiece is short, the simulation will be restricted in a short time period.

In this process, the force calculation is restricted by variable integral limitations determined by the dynamic entry angle and the exit angle. In the milling process, the entry angle $\phi_{\text {st }}$ is defined in the cutter coordinate system. It indicates the position where the cutter edge on a particular disk will immediately enter the workpiece. The exit angle $\phi_{\mathrm{ex}}$ is defined as the angle where the cutter tooth will leave the workpiece. As shown in Figure 5, when the instantaneous cutter edge position angle on a disk satisfies $\phi_{\mathrm{st}}<\psi_{i, j}<\phi_{\mathrm{ex}}$, there will be cutting forces imposed on this edge. The cutting forces on the cutter are the summary of forces imposed on all the disks in contact with the workpiece, which could be expressed as

$$
\begin{aligned}
& {\left[\begin{array}{l}
F_{x}(t) \\
F_{y}(t) \\
F_{z}(t)
\end{array}\right]=\sum_{i=1}^{N} \sum_{j=1}^{M} g\left(\psi_{i, j}(t)\right)\left[\begin{array}{l}
F_{x, i, j}(t) \\
F_{y, i, j}(t) \\
F_{z, i, j}(t)
\end{array}\right],} \\
& g\left(\psi_{i, j}(t)\right)= \begin{cases}1, & \text { if } \phi_{\mathrm{st}}<\psi_{i, j}(t)<\phi_{\mathrm{ex}}, \\
0, & \text { others. }\end{cases}
\end{aligned}
$$

In the entering process or other situations where the contact condition changes, the values are time-varied ones. Therefore, the entry angle $\phi_{\text {dst }}(t)$ and the exit angle $\phi_{\text {dex }}(t)$ should be updated dynamically in the simulation process. While updating these angles, the undeformed chip thickness on the edge should be determined first. Since the trajectories 


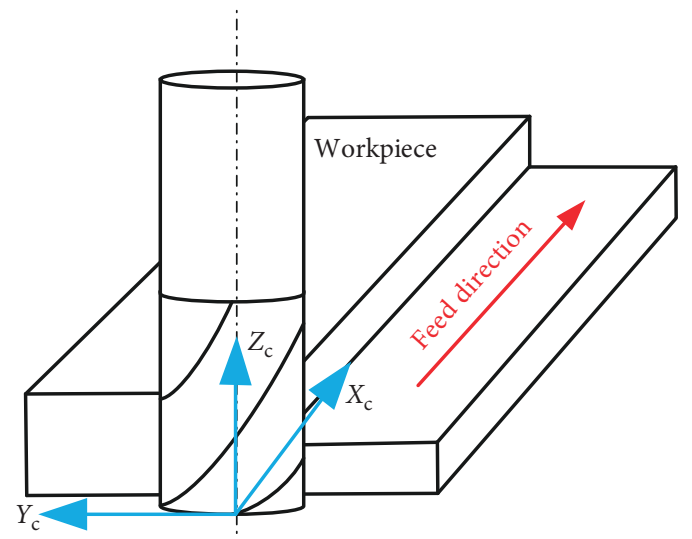

FiguRE 4: Cutter entering workpiece.

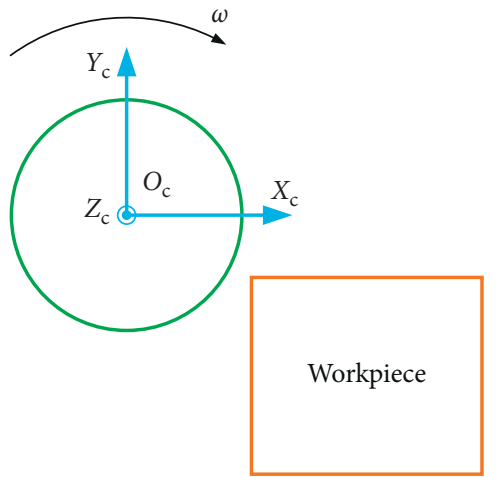

(a)

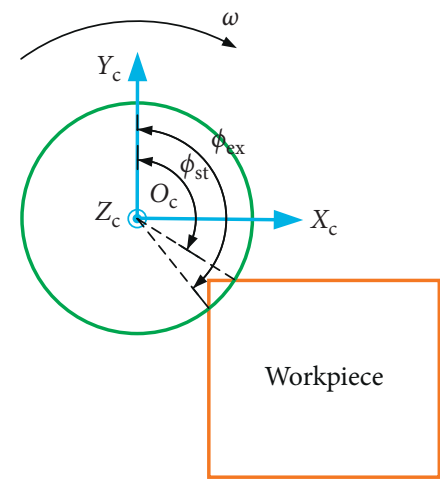

(b)

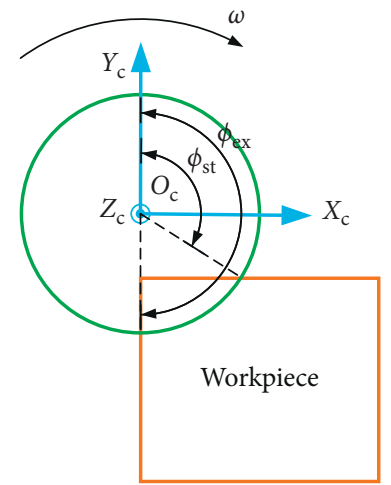

(c)

Figure 5: Division of the total procedure. (a) Uncontacted stage; (b) entering stage; (c) stable stage.

of edges are still cycloid, the variation of undeformed chip thickness could still be represented by Equation (2). The only requirement is to determine whether edges are in contact with the workpiece or not. This could be ensured by the dynamic entry angle and dynamic exit angle: once the envelope of the cutter touches the workpiece boundary, the calculation of $\phi_{\mathrm{dst}}(t)$ and $\phi_{\mathrm{dex}}(t)$ will start. According to Equation (14), the contact status of all disks at arbitrary sampling time $t$ will be determined and cutting forces can be calculated. The vital step for prediction is to determine the instantaneous entry and exit angles, which are tightly connected with the immersion condition. Generally, the entering procedure can be divided into three stages: uncontacted stage, entering stage, and stable stage, as shown in Figure 5.

In the uncontacted stage, the cutter is out of the workpiece, all components of cutting forces are zero. In the stable stage, the cutter-workpiece contact is stable and is possible to be calculated by the traditional method. However, in the entering stage, the contact situation between the cutter and the workpiece changes with the position of the cutter. To identify these three stages, the moving distance of a cutter from the starting point is used to divide the three stages. Three distances $s_{1}, s_{2}$, and $s_{3}$ are used as the critical positions of different stages, as shown in Figure 6.

As shown by Figure 6, when a cutter is moving toward the workpiece, the entering process starts in different ways, which is affected by the radial depth of cut. And the values of $s_{1}$ and $s_{2}$ also depend on the radial depth of cut. The two situations $\left(a_{\mathrm{e}}>R\right.$ and $\left.a_{\mathrm{e}}<R\right)$ are shown in Figure 7.

To calculate $s_{1}, s_{2}$, and $s_{3}$, the distance $\left(s_{0}\right)$ between starting point and boundary of the workpiece as well as the total displacement $(S)$ of the cutter in the simulation time is introduced here. By using the entry angle $\phi_{\mathrm{st}}$ and exit angle $\phi_{\text {ex }}$ of the stable stage, $s_{1}, s_{2}$, and $s_{3}$ could be expressed as

$$
\begin{aligned}
& s_{1}=\left\{\begin{array}{l}
s_{0}-R \sin \phi_{\mathrm{st}}, 0 \leq a_{\mathrm{e}} \leq R, \text { down milling, } \\
s_{0}-R \sin \phi_{\mathrm{ex}}, 0 \leq a_{\mathrm{e}} \leq R, \text { up milling, } \\
s_{0}-R, R<a_{\mathrm{e}} \leq D, \text { up and down milling, }
\end{array}\right. \\
& s_{2}=s_{0}, \\
& s_{3}=S .
\end{aligned}
$$

As shown in Figure 8, the variation and calculation of dynamic entry and exit angle are affected by the milling 


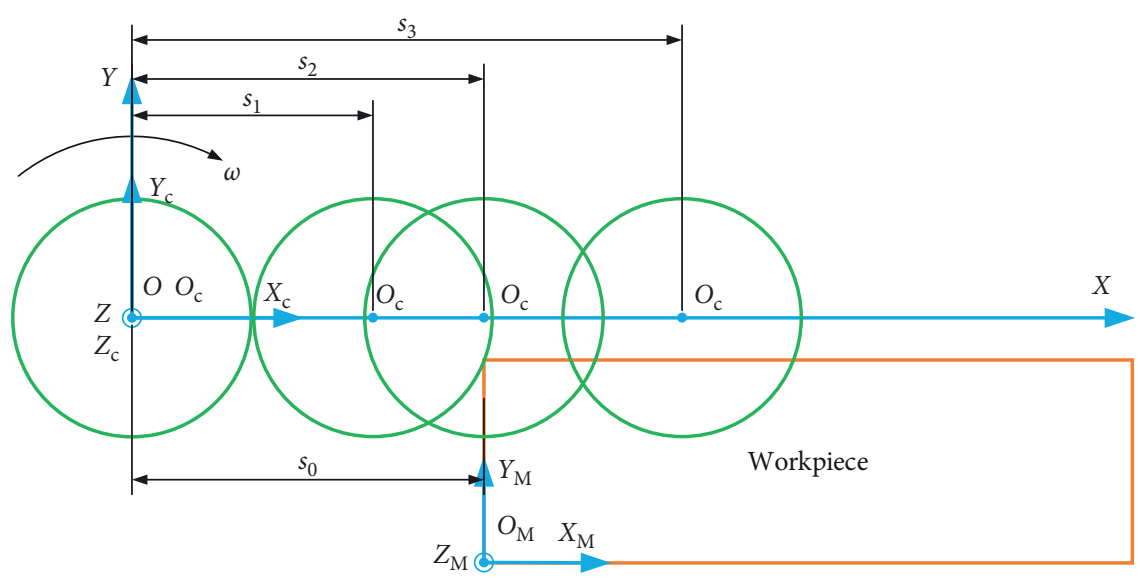

FIGURE 6: Cutter position and different contact stages.

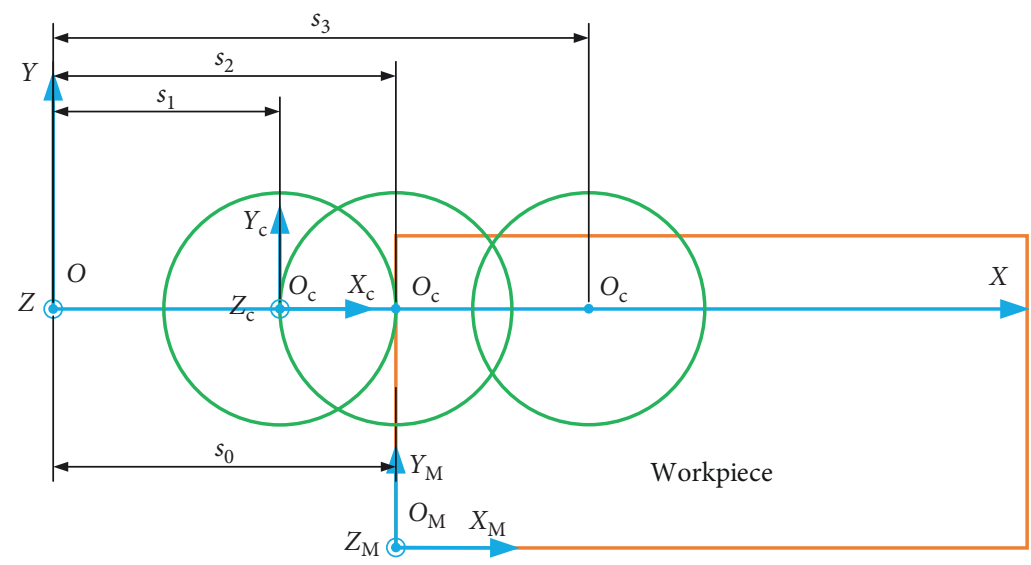

(a)

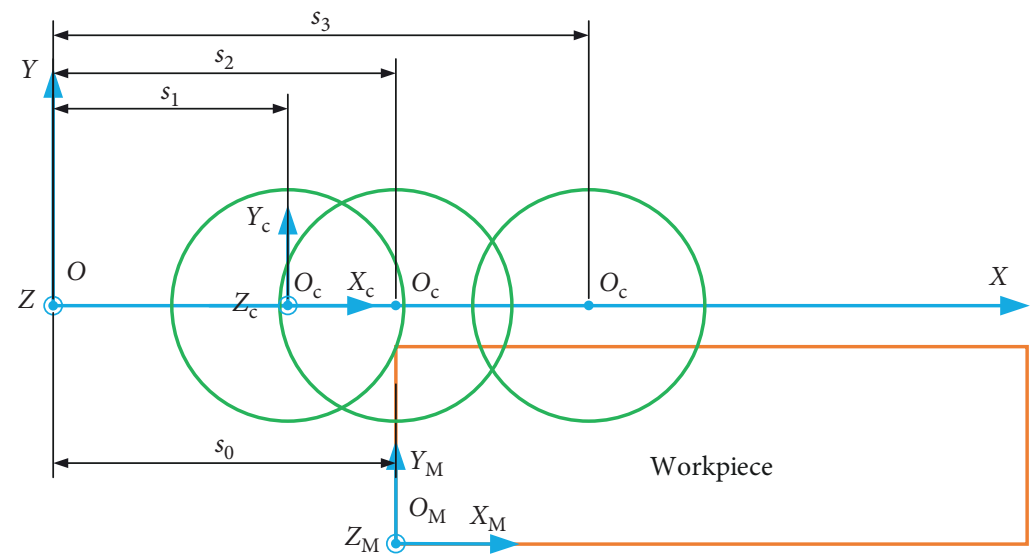

(b)

FIGURE 7: Cutter entering process with different radial cutting depths. (a) $a_{\mathrm{e}}>R$. (b) $a_{\mathrm{e}}<R$.

types and the radial depth of cut. In the entering process, when $a_{\mathrm{e}}<R$, the entry angle and exit angle in up milling and down milling vary in fixed modes and are irrelevant to the cutter position. However, when $a_{\mathrm{e}}<R$, the entry angle in down milling and the exit angle in up milling will stop changing after the cutter reaches a special position, while the exit angle in down milling and the entry angle in up milling keep changing.

By analyzing cutter-workpiece contact variation in Figure 8 , it can be seen that the dynamic entry angle and 
dynamic exit angle change with the cutter's position. In an entering stage with down milling, the dynamic entry angle and exit angle are calculated by the following formula:

$$
\left\{\begin{array}{l}
\phi_{\mathrm{dst}}(t)= \begin{cases}\phi_{\mathrm{st}}, & a_{\mathrm{e}}<R, \\
\sin ^{-1}\left(\frac{R-s(t)+s_{1}}{R}\right), & a_{\mathrm{e}}>R, s(t)<s_{1}+R-R \sin \phi_{\mathrm{st}}, \\
\phi_{\mathrm{st}}, & a_{\mathrm{e}}>R, s(t)>s_{1}+R-R \sin \phi_{\mathrm{st}},\end{cases} \\
\phi_{\mathrm{dex}}(t)= \begin{cases}\pi-\sin ^{-1}\left(\frac{R \sin \phi_{\mathrm{st}}-s(t)+s_{1}}{R}\right), & a_{\mathrm{e}}<R, \\
\pi-\sin \left(\frac{R-s(t)+s_{1}}{R}\right), & a_{\mathrm{e}}>R .\end{cases}
\end{array}\right.
$$

Similarly, the dynamic entry angle and exit angle, in an entering stage with up milling, could be calculated by

$$
\left\{\begin{array}{l}
\phi_{\mathrm{dst}}(t)= \begin{cases}\sin ^{-1}\left(\frac{R \sin \phi_{\mathrm{st}}-s(t)+s_{1}}{R}\right), & a_{\mathrm{e}}<R, \\
\sin ^{-1}\left(\frac{R-s(t)+s_{1}}{R}\right), & a_{\mathrm{e}}>R,\end{cases} \\
\phi_{\mathrm{dex}}(t)= \begin{cases}\phi_{\mathrm{ex}}, & a_{\mathrm{e}}<R, \\
\pi-\sin \left(\frac{R-s(t)+s_{1}}{R}\right), & a_{\mathrm{e}}>R, s(t)>s_{1}+R-R \sin \phi_{\mathrm{st}}, \\
\phi_{\mathrm{ex}}, & a_{\mathrm{e}}>R, s(t)>s_{1}+R-R \sin \phi_{\mathrm{st}} .\end{cases}
\end{array}\right.
$$

In Equations (16) and (17), the dynamic entry angle and dynamic exit angle are represented by $\phi_{\mathrm{dst}}(t)$ and $\phi_{\mathrm{dex}}(t)$, respectively. They could be directly calculated by using the radial depth of cut and the milling type.

3.2. Analytical Modeling of the Cutter Entering along a Circular Path. In the practical machining process, the cutter may enter from the machined/unmachined surface of the workpiece instead of the workpiece boundary due to the path planning strategy or tool change. This stage is usually unstable and may leave vibration marks on the machined surface. To describe this situation in detail and provide support for the vibration control method, a simulation model will be developed. A typically used toolpath is to let the cutter enter by following a circular path, as shown in Figure 9.

While the cutter is entering along a circular path, the origin of a static coordinate system (SCS) is fixed to the center of the tool path; $x$-axis is perpendicular to the tool axis, and $z$-axis is parallel with the tool axis. The radius of the circular path is $R_{1}=H R$ ( $R$ is radius of the cutter, and $H$ is the ratio of the cycle path radius to cutter radius). In Figure 9, $\omega$ is the angular speed of the cutter autorotation and $\omega_{1}$ is the angular speed for the cutter rotating around the origin of the circular path, and they are expressed as

$$
\begin{gathered}
\omega=\frac{2 \pi n}{60}, \\
\omega_{1}=\frac{f}{R_{1}},
\end{gathered}
$$

where $f(\mathrm{~mm} / \mathrm{min})$ is the feed rate of the cutter and $n(\mathrm{rpm})$ is the spindle speed. Besides, $\theta(t)=\omega_{1} t$ is the angle position of cutter, and $\theta_{1}$ is the critical position before the cutter entering the workpiece:

$$
\theta_{1}=\arccos \left(\frac{R_{1}-a_{\mathrm{e}}}{R_{1}}\right) .
$$

Then, the time moment $t_{1}$ after which cutter-workpiece contact will be stable is

$$
t_{1}=\frac{\pi}{2 \omega_{1}}
$$

After $t_{1}$, the cutter will go along a straight line for $s(\mathrm{~mm})$. Since the cutter coordinate system (CCS) is fixed to the cutter, directions of axes in CCS also change when the cutter is moving along the circular path. Their directions could be expressed by the following vectors:

$$
\begin{aligned}
& \overrightarrow{\mathbf{X}_{\mathrm{c}}(t)}= \begin{cases}{\left[\begin{array}{lll}
-\cos (\theta(t)) & \sin (\theta(t)) & 0
\end{array}\right],} & t \leq \frac{\pi}{2 \omega_{1}}, \\
{\left[\begin{array}{lll}
0 & 1 & 0
\end{array}\right],} & \frac{\pi}{2 \omega_{1}}<t \leq \frac{\pi}{2 \omega_{1}}+\frac{60 S}{f},\end{cases} \\
& \overrightarrow{\mathbf{Y}_{\mathrm{c}}(t)}= \begin{cases}{\left[\begin{array}{lll}
-\sin (\theta(t)) & -\cos (\theta(t)) & 0
\end{array}\right],} & t \leq \frac{\pi}{2 \omega_{1}}, \\
{\left[\begin{array}{lll}
-1 & 0 & 0
\end{array}\right],} & \frac{\pi}{2 \omega_{1}}<t \leq \frac{\pi}{2 \omega_{1}}+\frac{S}{f},\end{cases}
\end{aligned}
$$$$
\overrightarrow{\mathbf{Z}_{\mathrm{c}}(t)}=\left[\begin{array}{lll}
0 & 0 & 1
\end{array}\right], \quad t \leq \frac{\pi}{2 \omega_{1}}+\frac{S}{f}
$$

The position of the cutter center, which is also the original point of CCS, is expressed as

$$
O_{\mathrm{c}}(t)= \begin{cases}R_{1}\left[\begin{array}{ll}
-\sin (\theta(t))-\cos (\theta(t)) & 0
\end{array}\right], & t \leq \frac{\pi}{2 \omega_{1}}, \\
{\left[\begin{array}{ll}
-R_{1} f\left(t-\frac{\pi}{2 \omega_{1}}\right) & 0
\end{array}\right],} & \frac{\pi}{2 \omega_{1}}<t \leq \frac{\pi}{2 \omega_{1}}+\frac{S}{f} .\end{cases}
$$

By using the expression of CCS axes, cutting forces applied on the cutter can be transformed into the SCS: 


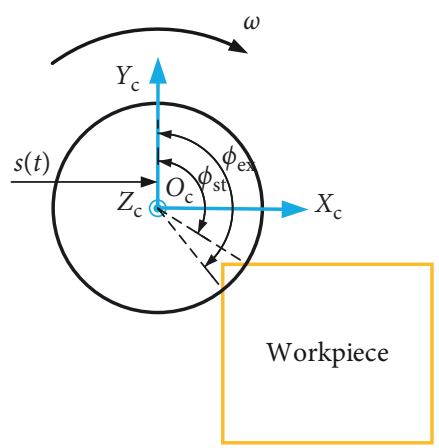

(a)

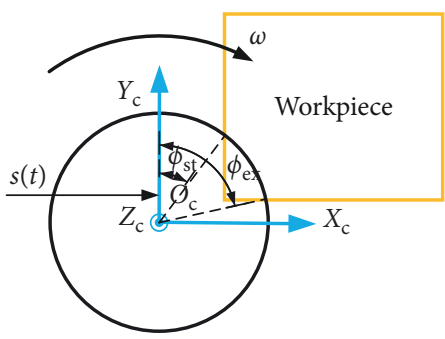

(c)
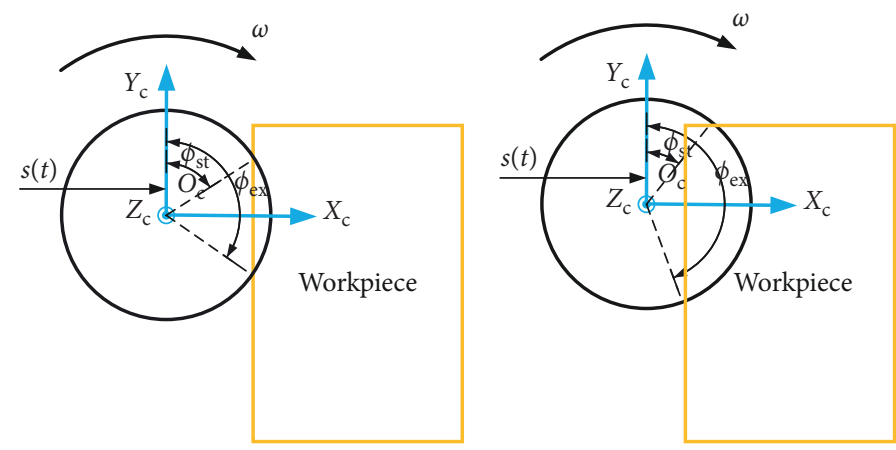

(b)
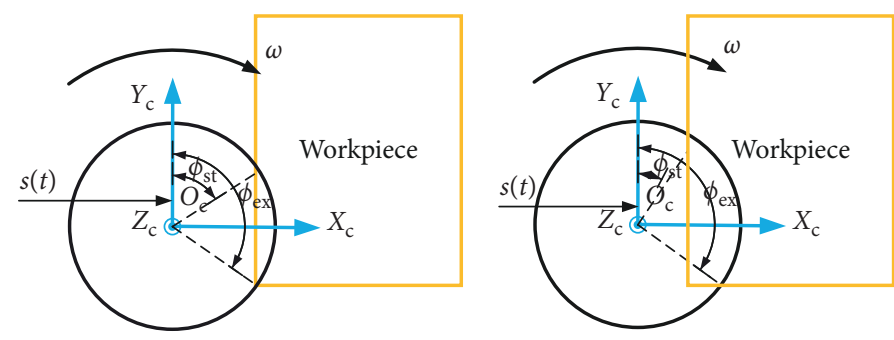

(d)

Figure 8: Calculation of the dynamic entry angle and exit angle in the entering stage. (a) $a_{\mathrm{e}}<R$, down milling. (b) $a_{\mathrm{e}}>R$, down milling. (c) $a_{\mathrm{e}}<R$, up milling. (d) $a_{\mathrm{e}}>R$, up milling.

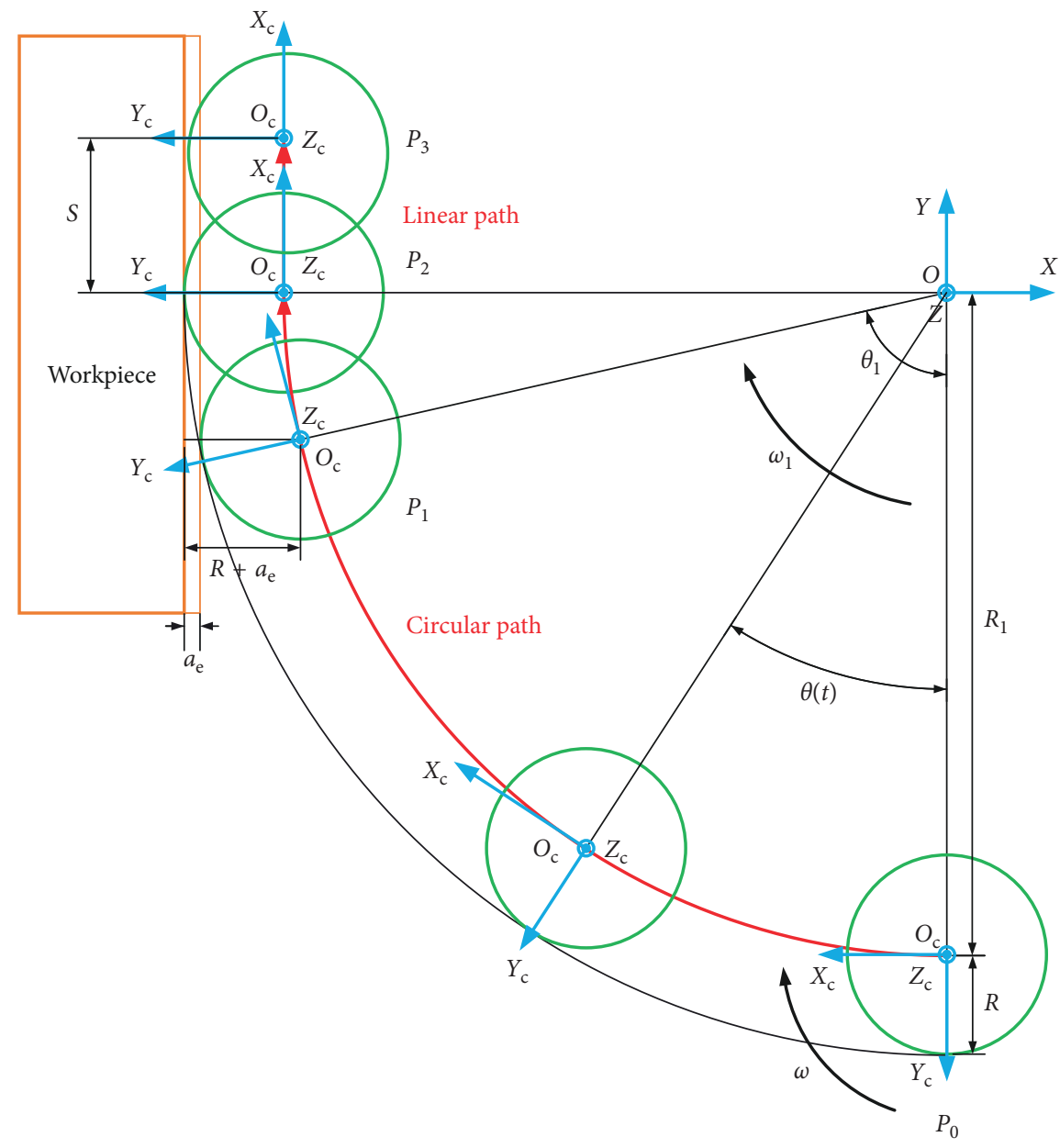

Figure 9: Cutter entering workpiece along a circular path. 


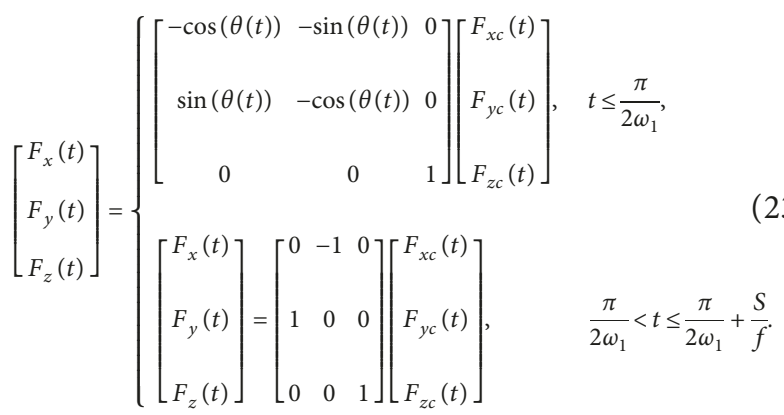

As shown in Figure 10, while a cutter is entering the workpiece along a circular path, the entering process could be divided into three stages. In the first stage, when $\theta(t)<\theta_{1}$, the cutter is out of the workpiece. Then, when $\theta_{1}<\theta(t)<\theta_{2}$, the entry angle and exit angle change with the moving cutter. In the third stage, the entry angle is zero while the exit angle keeps changing with the cutter movement.

To calculate the dynamic entry angle and dynamic exit angle, the geometric intersection of the unremoved material boundary and the cutter envelope is analyzed and shown in Figure 11. When the cutter reaches position 1, the entering process starts. Then, the cutter teeth will enter the workpiece at point $A_{1}$ and leave workpiece at point $B_{1}$. It is clear that $A_{1}$ and $B_{1}$ are actually the intersection points of the workpiece boundary and the circle of the cutter envelope. Representing unmachined surface of the workpiece with a static line and representing the cutter envelope of a cutter as a moving circle, the moving position of $A(t)$ and $B(t)$ could be obtained by using intersection point solution of line and cycle. Then, the entry angle and exit angle could be calculated by using the coordinates of $A(t)$ and $B(t)$. Besides, after cutter reaching position 2 , the entry angle will not change and stay as zero while the exit angle will vary until the cutter reaches the end of cycle path and starts moving along a straight line.

By using intersection point formula, the $y$ coordinates of $A(t)$ and $B(t)$ in the entering stage are

$$
\begin{aligned}
& y_{A}(t)=y_{\mathrm{c}}(t)-\sqrt{R^{2}-\left(\left(R+R_{1}\right)-a_{\mathrm{e}}+x_{\mathrm{c}}(t)\right)^{2}}, \\
& y_{B}(t)=y_{\mathrm{c}}(t)+\sqrt{R^{2}-\left(\left(R+R_{1}\right)-a_{\mathrm{e}}+x_{\mathrm{c}}(t)\right)^{2}} .
\end{aligned}
$$

Then, the coordinates of the intersection points are $A\left(a_{\mathrm{e}}-R_{1}, y_{A}(t), 0\right)$ and $B\left(a_{\mathrm{e}}-R_{1}, y_{B}(t), 0\right)$, and the vectors $\overrightarrow{\mathbf{O}_{\mathrm{c}} \mathbf{B}}$ and $\overrightarrow{\mathbf{O}_{\mathrm{c}} \mathbf{A}}$ can be expressed as

$$
\begin{aligned}
& \overrightarrow{\mathrm{O}_{\mathrm{c}} \mathrm{B}}=\overrightarrow{\mathrm{OB}}-\overrightarrow{\mathrm{OO}_{\mathrm{c}}}, \\
& \overrightarrow{\mathrm{O}_{\mathrm{c}} \mathrm{A}}=\overrightarrow{\mathrm{OA}}-\overrightarrow{\mathrm{OO}_{\mathrm{c}}}
\end{aligned}
$$

Using vector calculation, the dynamic entry angle and dynamic exit angle are

$$
\begin{aligned}
& \theta_{\mathrm{dst}}(t)= \begin{cases}\cos ^{-1}\left(\frac{\overrightarrow{\mathbf{O}_{\mathrm{c}} \mathbf{A}} \cdot \overrightarrow{\mathbf{O}_{\mathrm{c}} \mathbf{Y}_{\mathrm{c}}}}{\left|\overrightarrow{\mathbf{O}_{\mathrm{c}} \mathbf{A}}\right|}\right), & \theta_{1}<\theta(t)<\theta_{2}, \\
0, & \theta_{2}<\theta(t),\end{cases} \\
& \theta_{\mathrm{dex}}(t)=\cos ^{-1}\left(\frac{\overrightarrow{\mathbf{O}_{\mathrm{c}} \mathbf{B}} \cdot \overrightarrow{\mathbf{O}_{\mathrm{c}} \mathbf{Y}_{\mathrm{c}}}}{\left.\mid \overrightarrow{\mathbf{O}_{\mathrm{c}} \mathbf{B}}\right) .}\right.
\end{aligned}
$$

The dynamic entry angle and the dynamic exit angle in Equation (26) should be calculated to calculate the instantaneous cutting forces. Then, by synthesizing all derivation from Equation (1) to Equation (26), the whole program of the two conditions is established and shown in Figure 12. In the calculation procedure, the initial values of the velocity and displacement in the system dynamic equations (Equation (4)) are set to zero. The simulation procedure shown in Figure 12 can be divided into the following steps. (1) The necessary parameters for simulation and the entering type are given. (2) At each time $t$, the position of the cutter will be calculated with the instantaneous immersion angle and exit angle. (3) At the same time, the dynamic undeformed chip thickness is calculated using the stored displacements of the cutter. (4) Cutting forces are calculated. (5) Both the real-time cutting forces and cutter displacements are stored. (6) If the position of the cutter reaches the end point, the whole calculation procedure is ended and results will be output. Otherwise, the program will return to Step (2) to calculate next sampling time.

\section{Experimental Validation and Discussion}

In this section, to validate the developed model for simulating the cutter entering the workpiece from the boundary or along a circular path, both simulations and experiments are carried out and compared. The modal test for the cutter stiffness parameters and the cutting tests for cutting force coefficient identification were carried out first. By comparing measured results and predicted results, advantages and disadvantages of the developed model are discussed. Besides, the predicted cutter vibration and actual cutter vibration in the cutting tests will be compared. The parameters for the cemented carbide end milling cutter utilized in the experiments are shown in Table 1.

The machine tool used is a YH850 4-axis machining center, and a Kistler 9255B dynamometer was used for measuring forces. The matched Kistler 5080 charge amplifier and a 6-channel data acquisition device were used in the experiments. A 45-steel workpiece was machined without a coolant. A Kistler 9722A500 impact hammer and a Dytran $3225 \mathrm{~F} 1$ acceleration sensor were used in the impact test. In all machining tests, the sampling frequency was set to $20000 \mathrm{~Hz}$. 


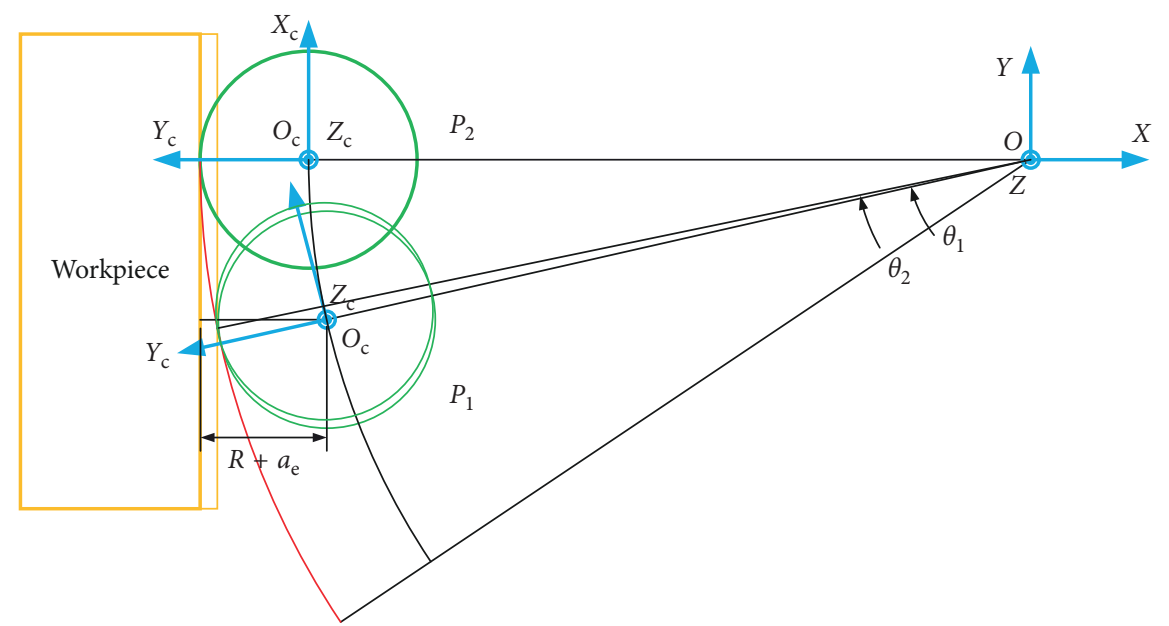

Figure 10: Different stages for the cutter entering workpiece along a circular path.

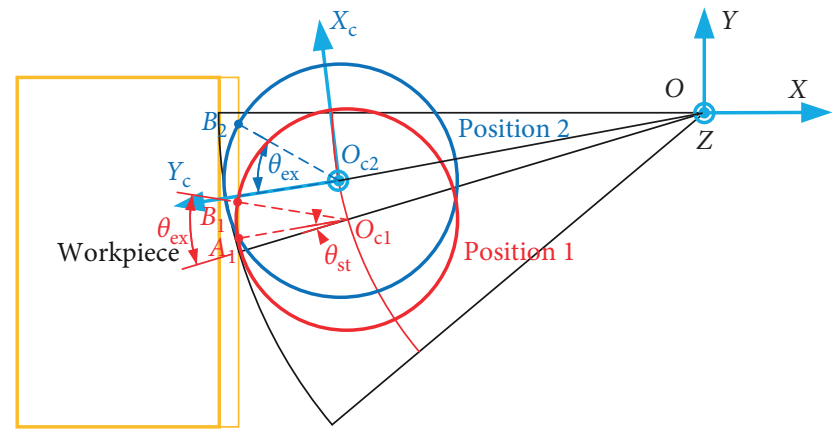

Figure 11: The dynamic entry and exit angles.

4.1. Modal Test and Cutting Force Coefficient Identification. The cutting conditions used for the cutting force coefficient identification are shown in Table 2. The experimental setup is shown in Figure 13. The modal test results and identification results are shown in Table 3.

4.2. Cutting Tests with the Cutter Entering from the Boundary of a Workpiece. The cutting conditions for a cutter entering from the workpiece boundary is shown in Table 4, and the recorded cutting forces will be used for comparison with the simulation results.

The simulated and measured cutting forces are compared in Figure 14, and the simulated and measured cutter vibrations are shown in Figure 15. Particularly, for the rotation of the cutter and discontinuous contact between the cutter teeth and the workpiece, it is difficult to measure the displacements of the cutter in the milling process. The displacements of the cutter are calculated through the classical fourth-order Runge-Kutta method [4, 29] by using the measured cutting force signals and the system dynamic equations (Equation (4)), and the measured modal parameters are used here. For example, the displacements of the cutter in the $x$ direction at time $t_{k}$ are

$$
\begin{aligned}
& x\left(t_{k+1}\right)=x\left(t_{k}\right)+\frac{h}{6}\left(K_{1}+2 K_{2}+2 K_{3}+K_{4}\right), \\
& x_{1}\left(t_{k+1}\right)=x_{1}\left(t_{k}\right)+\frac{h}{6}\left(L_{1}+2 L_{2}+2 L_{3}+L_{4}\right),
\end{aligned}
$$

where $x_{1}\left(t_{k+1}\right)$ and $x_{1}\left(t_{k}\right)$ are the velocity of the cutter at $t_{k+1}$ and $t_{k}$. The intermediate variables $L_{1}, L_{2}, L_{3}, L_{4}$ and $K_{1}, K_{2}, K_{3}, K_{4}$ are calculated by

$$
\left\{\begin{array}{l}
\left\{\begin{array}{l}
K_{1}=x_{1}\left(t_{k+1}\right), \\
K_{2}=x_{1}\left(t_{k+1}\right)+\frac{h}{2} L_{1}, \\
K_{3}=x_{1}\left(t_{k+1}\right)+\frac{h}{2} L_{2}, \\
K_{4}=x_{1}\left(t_{k+1}\right)+\frac{h}{2} L_{3}, \\
L_{1}=-\frac{c_{x}}{M_{x}} x_{1}\left(t_{k+1}\right)-\frac{k_{x}}{M_{x}} x\left(t_{k}\right)+\frac{F_{x}\left(t_{k}\right)}{M_{x}}, \\
L_{2}=-\frac{c_{x}}{M_{x}}\left[x_{1}\left(t_{k+1}\right)+\frac{h}{2} L_{1}\right]-\frac{k_{x}}{M_{x}}\left[x\left(t_{k}\right)+\frac{h}{2} K_{1}\right]+\frac{F_{x}\left(t_{k}+(h / 2)\right)}{M_{x}}, \\
L_{3}=-\frac{c_{x}}{M_{x}}\left[x_{1}\left(t_{k+1}\right)+\frac{h}{2} L_{2}\right]-\frac{k_{x}}{M_{x}}\left[x\left(t_{k}\right)+\frac{h}{2} K_{2}\right]+\frac{F_{x}\left(t_{k}+(h / 2)\right)}{M_{x}}, \\
L_{4}=-\frac{c_{x}}{M_{x}}\left[x_{1}\left(t_{k+1}\right)+h L_{3}\right]-\frac{k_{x}}{M_{x}}\left[x\left(t_{k}\right)+h K_{3}\right]+\frac{F_{x}\left(t_{k}+h\right)}{M_{x}} .
\end{array}\right.
\end{array}\right.
$$

By comparing the simulated results with the measured values in Figures 14 and 15, including the forces and displacements in two directions, it could be concluded that the general trends of predicted results match well with the measured ones. However, one nonnegligible problem is that the maximum values of measured forces are larger than those of predicted results. To discuss the potential reasons, a section of forces acquired in Test No. 1 is zoomed in and 


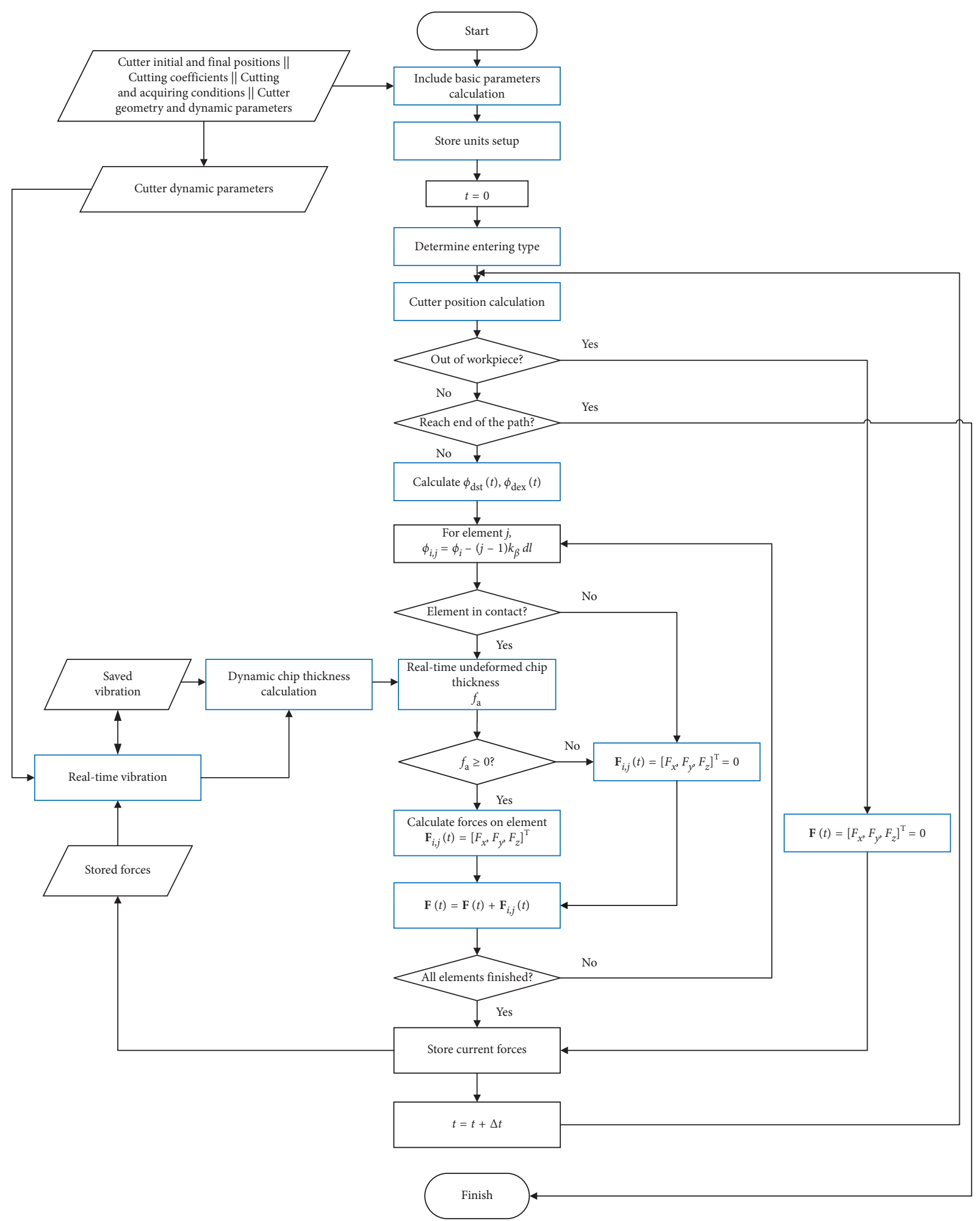

Figure 12: Flow chart of the cutter entering workpiece for two conditions.

TABLE 1: Cutter geometry parameters.

\begin{tabular}{lcccc}
\hline Helical angle & Diameter $(\mathrm{mm})$ & Length of cutter $(\mathrm{mm})$ & Length of cutting flutes $(\mathrm{mm})$ & Number of teeth \\
\hline $30^{\circ}$ & 12 & 72 & 22 & 2 \\
\hline
\end{tabular}


TABLE 2: Cutting conditions for the cutting force coefficients identification.

\begin{tabular}{lccccc}
\hline Test No. & Milling type & Radial depth of cut $a_{\mathrm{e}}(\mathrm{mm})$ & Axial depth of cut $a_{\mathrm{p}}(\mathrm{mm})$ & Feed per tooth $f_{\mathrm{z}}(\mathrm{mm} /$ tooth $)$ & Spindle speed $(\mathrm{rpm})$ \\
\hline 1 & Down/slotting & 10 & 0.6 & 0.03 & 1000 \\
2 & Down/slotting & 10 & 0.6 & 0.04 & 1000 \\
3 & Down/slotting & 10 & 0.6 & 0.06 & 1000 \\
4 & Down/slotting & 10 & 0.6 & 0.08 & 1000 \\
5 & Down/slotting & 10 & 0.6 & 0.10 & 1000 \\
\hline
\end{tabular}

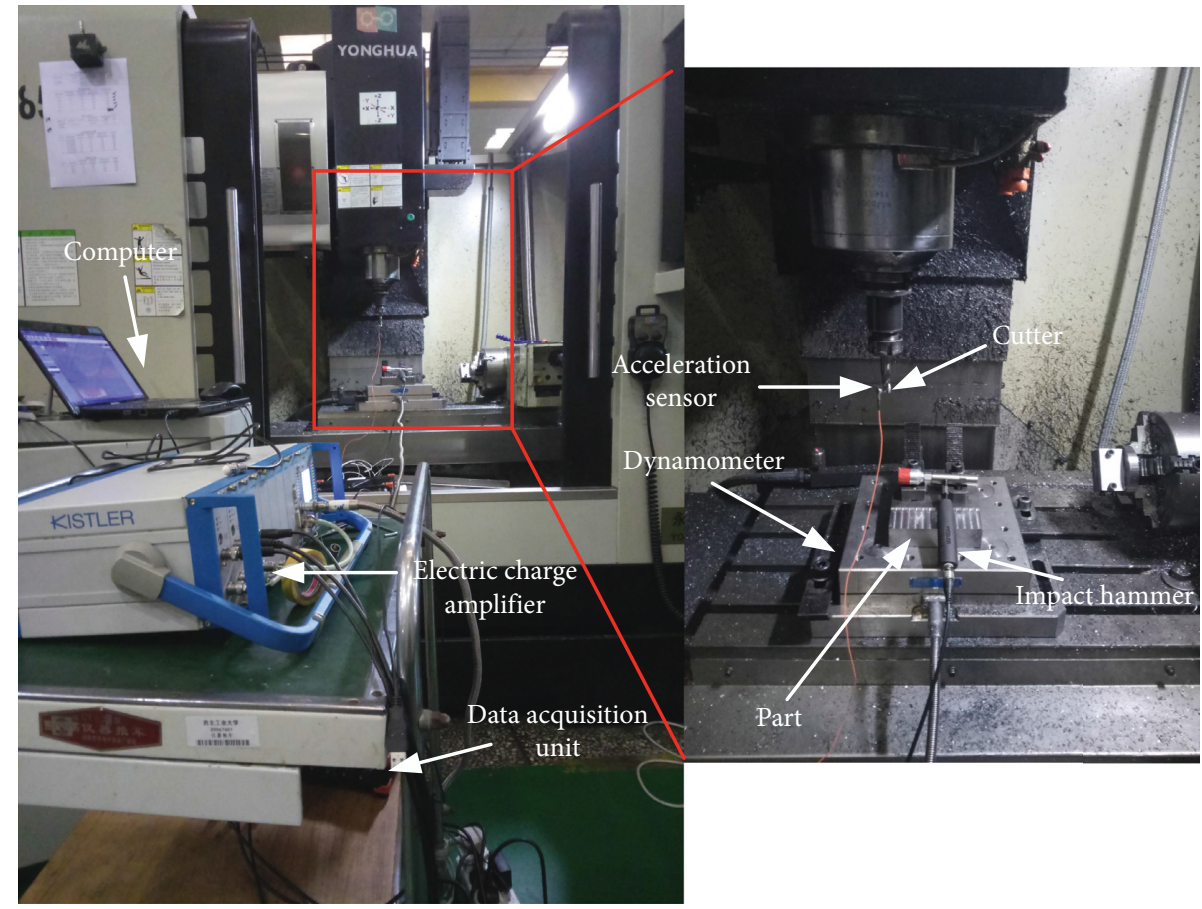

Figure 13: Setup of cutting experiments and impact tests.

TABLE 3: Modal parameters of cutter and cutting force coefficients.

\begin{tabular}{lccc}
\hline$k_{x} / k_{y}(\mathrm{~N} / \mathrm{m})$ & $c_{x} / c_{y}(\mathrm{~N} /(\mathrm{m} / \mathrm{s}))$ & \multicolumn{2}{c}{$m_{x} / m_{y}(\mathrm{~kg})$} \\
$1.74 \times 10^{7}$ & 116.4931 & \multicolumn{2}{c}{0.2198} \\
\hline$K_{\mathrm{tc}}\left(\mathrm{N} / \mathrm{mm}^{2}\right)$ & $K_{\mathrm{te}}(\mathrm{N} / \mathrm{mm})$ & $K_{\mathrm{rc}}\left(\mathrm{N} / \mathrm{mm}^{2}\right)$ & $K_{\mathrm{re}}(\mathrm{N} / \mathrm{mm})$ \\
2129.9 & 28.6524 & 946.7411 & 18.1387 \\
& & &
\end{tabular}

matched with the simulated forces according to the time axis, as shown in Figure 16.

In Figure 16, the forces on two teeth in one cycle are not equal when they are at the same position. Normally, the chip thickness on different teeth varies in the same way under stable cutter-workpiece contact. But in the actual machining process, the cutter runout caused by the misalignment of cutter axis and spindle rotation axis will result in the redistribution of load on teeth [30]. Therefore, the forces on one tooth are higher than the other one. Besides, since the periodic forces on each tooth are different, the vibration of the cutter shows the same trend. At the starting stage of entering, the cutter-workpiece contact varies seriously where the cutter runout may have more significant influence. Since the cutting forces and cutter vibration are coupled, this could be responsible for the differences between simulated results and experimental results shown in Figures 15(b) and 15(c). As for the relatively rough measured signals compared with simulated results, this could be attributed to the crap of chips, environment noise, equipment interference, and so on, which cannot be modeled by the traditional cutting force model.

\subsection{Cutting Tests with the Cutter Entering along a Circular} Path. The cutting conditions used for experiments with cutter entering along a circular path are shown in Table 5, and a circular path is shown in Table 6, with the simulation times of different cases being shown in Table 7. Recorded and simulated forces are shown in Figure 17.

In Figures 17 and 18, all simulated results are approximate to the measured results, which means the prediction model is effective under the experimental conditions. Except the phenomena discussed in the former section, the measured results in this group of experiments in the $y$ direction are a bit smaller. Another obvious difference between the predicted results and measured results is the strident gap of forces between cycle movement and straight-line movement of the cutter, which is shown in Figure 19. This is largely due to the fact that the established model is a mechanistic model instead of an integrated electronic-mechanistic model, which means the kinematics of the feed drive systems are not considered by the 
TABLE 4: Cutting conditions for a cutter entering from the workpiece boundary.

\begin{tabular}{lccccc}
\hline Test No. & Milling type & Radial depth of cut $a_{\mathrm{e}}(\mathrm{mm})$ & Axial depth of cut $a_{\mathrm{p}}(\mathrm{mm})$ & Feed per tooth $f_{\mathrm{z}}(\mathrm{mm} /$ tooth$)$ & Spindle speed \\
\hline 1 & Down & 12 & 0.2 & 0.05 & 0.05 \\
2 & Down & 12 & 0.4 & 0.05 & 1000 \\
3 & Down & 12 & 0.6 & 0.04 & 1000 \\
4 & Down & 8 & 1 & 0.10 & 1000 \\
5 & Down & 8 & 1 & 0.05 & 1000 \\
6 & Down & 5 & 1.6 & 0.08 & 1000 \\
7 & Down & 5 & 0.8 & 0.12 & 1000 \\
8 & Down & 3 & 1.5 & 1000 \\
\hline
\end{tabular}
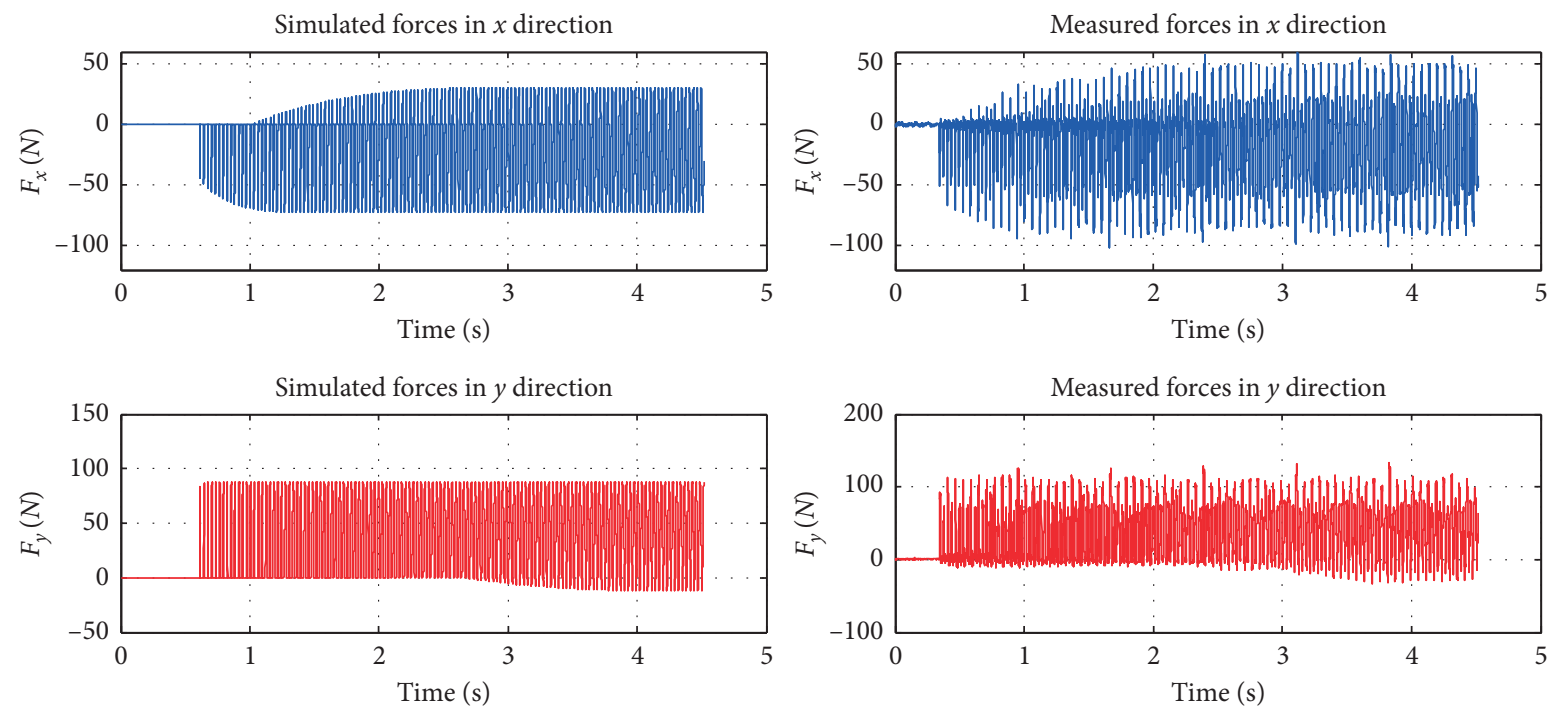

(a)
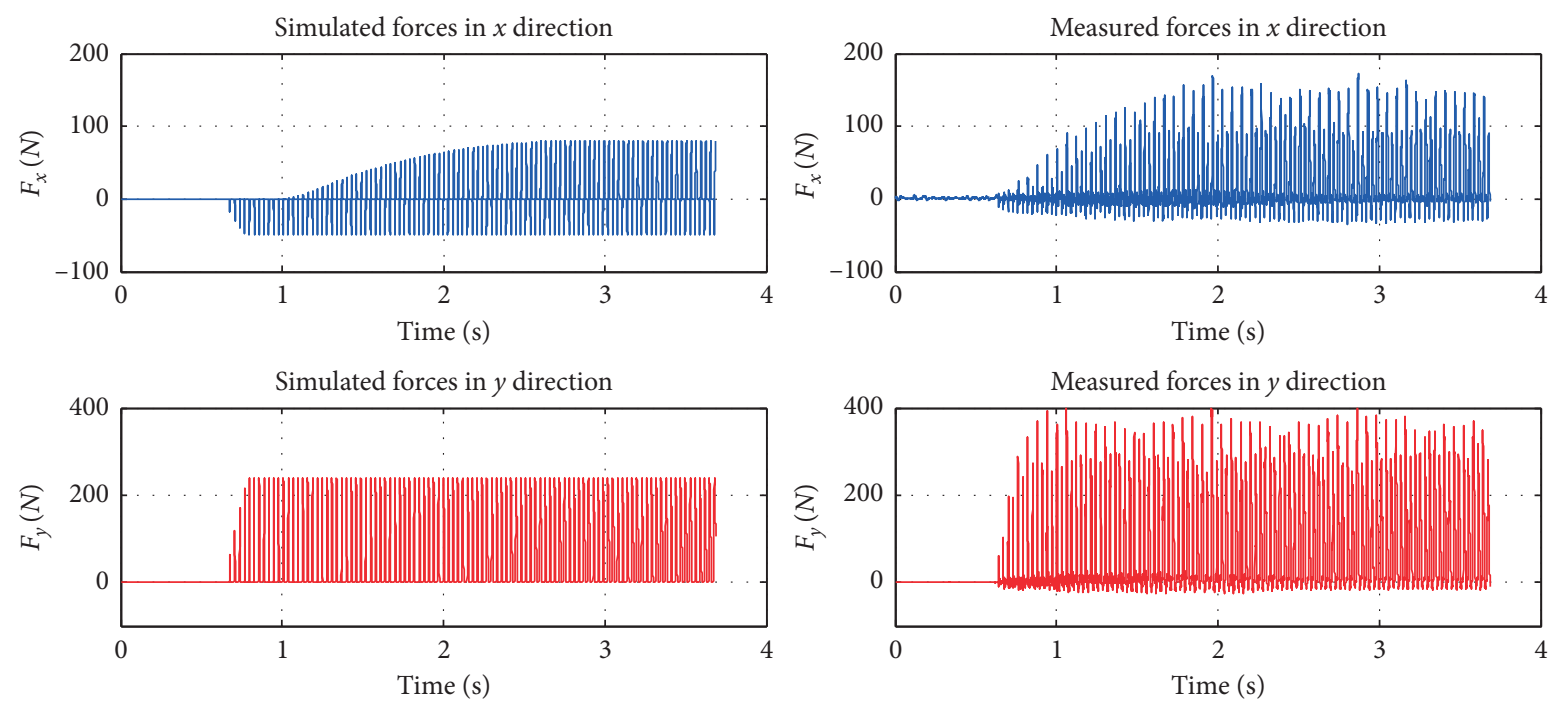

(b)

Figure 14: Continued. 

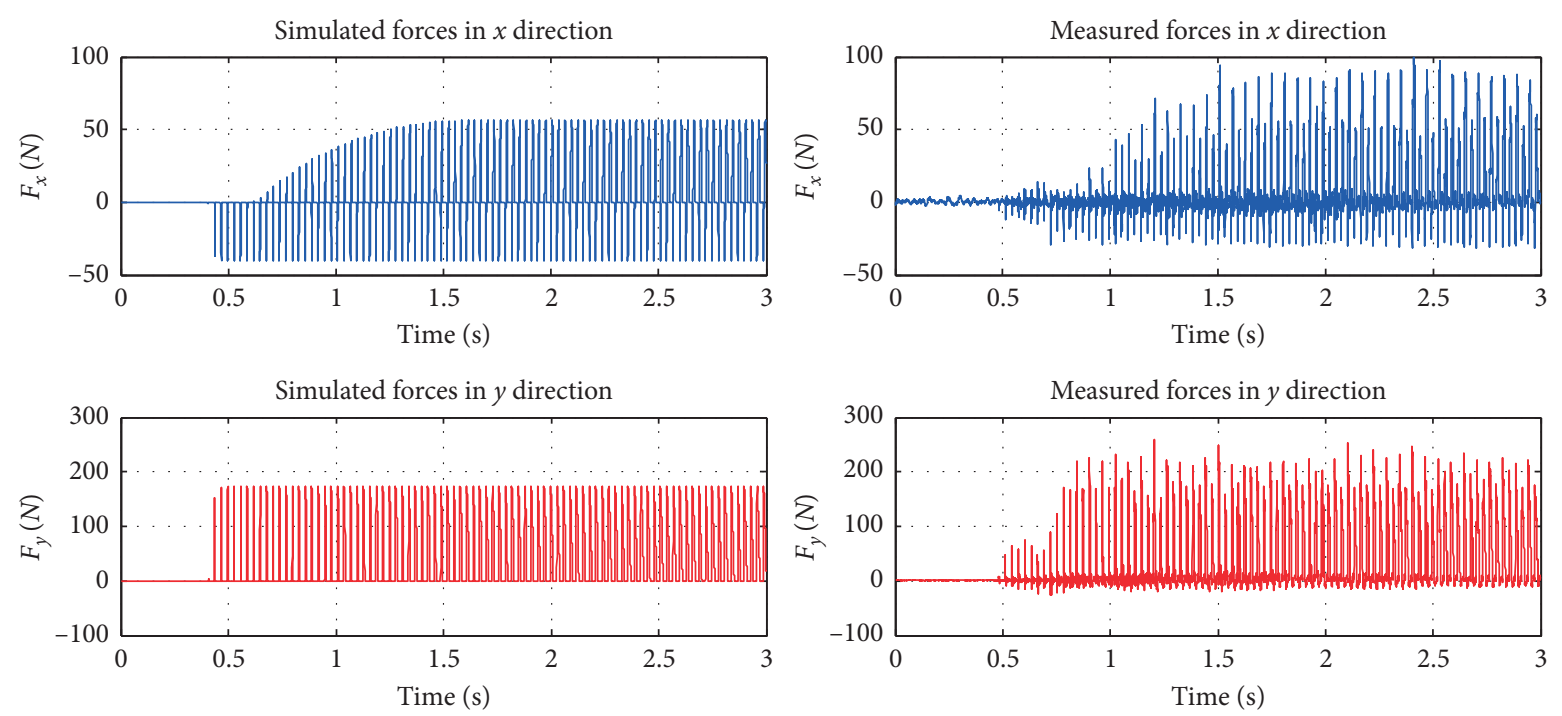

(c)
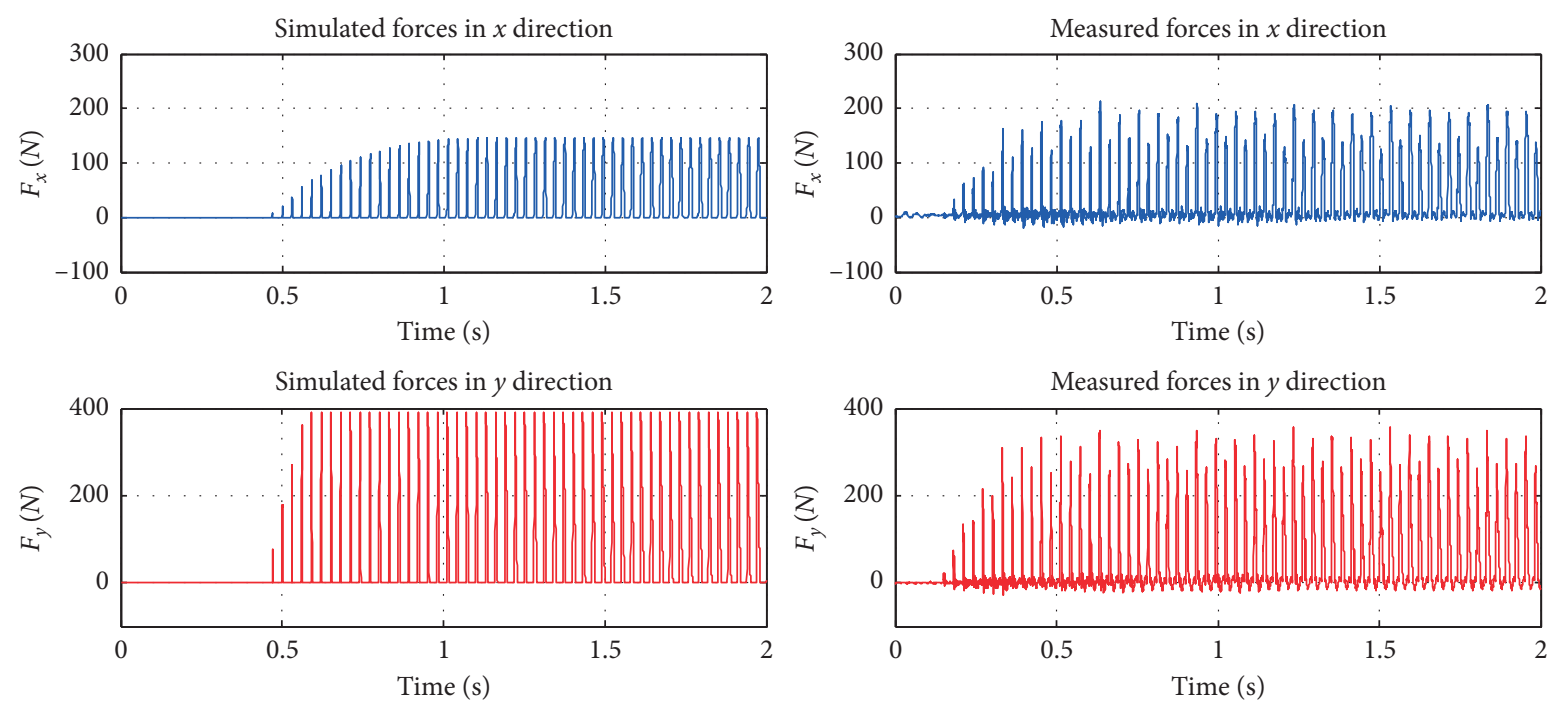

(d)

Figure 14: Simulated and measured forces when the cutter entering the workpiece along a straight line: (a) Test No. 3, (b) Test No. 6, (c) Test No. 7, and (d) Test No. 8.

model. And the machine tool used takes an unsmooth switch from the cycle feed mode to straight-line feed mode, resulting in the gap of forces in experiments.

\section{Conclusion}

A novel model for analyzing the flat-end cutter entering the workpiece process is developed, simulated, and validated with experiments. The developed model can be directly used for predicting cutting forces and the dynamic displacements of the cutter in the entering process where the cutting conditions keep changing. In this situation, the simulation results of the entering process enable the process designers to analyze the dynamic response of the entering process in which way the action of dealing with possible vibration marks could be prepared. It can be further used for vibration control in the entering process. Among the simulation results, it can be clearly seen that the entering type and parameters could greatly affect the vibration. By using the optimization method and vibration suppression method, it is possible to decrease vibration at particular positions, such as the design of cutters based on the above analysis to suppress vibration during entering process. The main contributions of this paper can be concluded as follows:

(1) A time-domain cutting force model for the cutter entering process by considering the cutter dynamics is presented

(2) A straight-line entering model of the cutter from the workpiece boundary is presented by analyzing the dynamic entry angle and exit angle in the corresponding process 

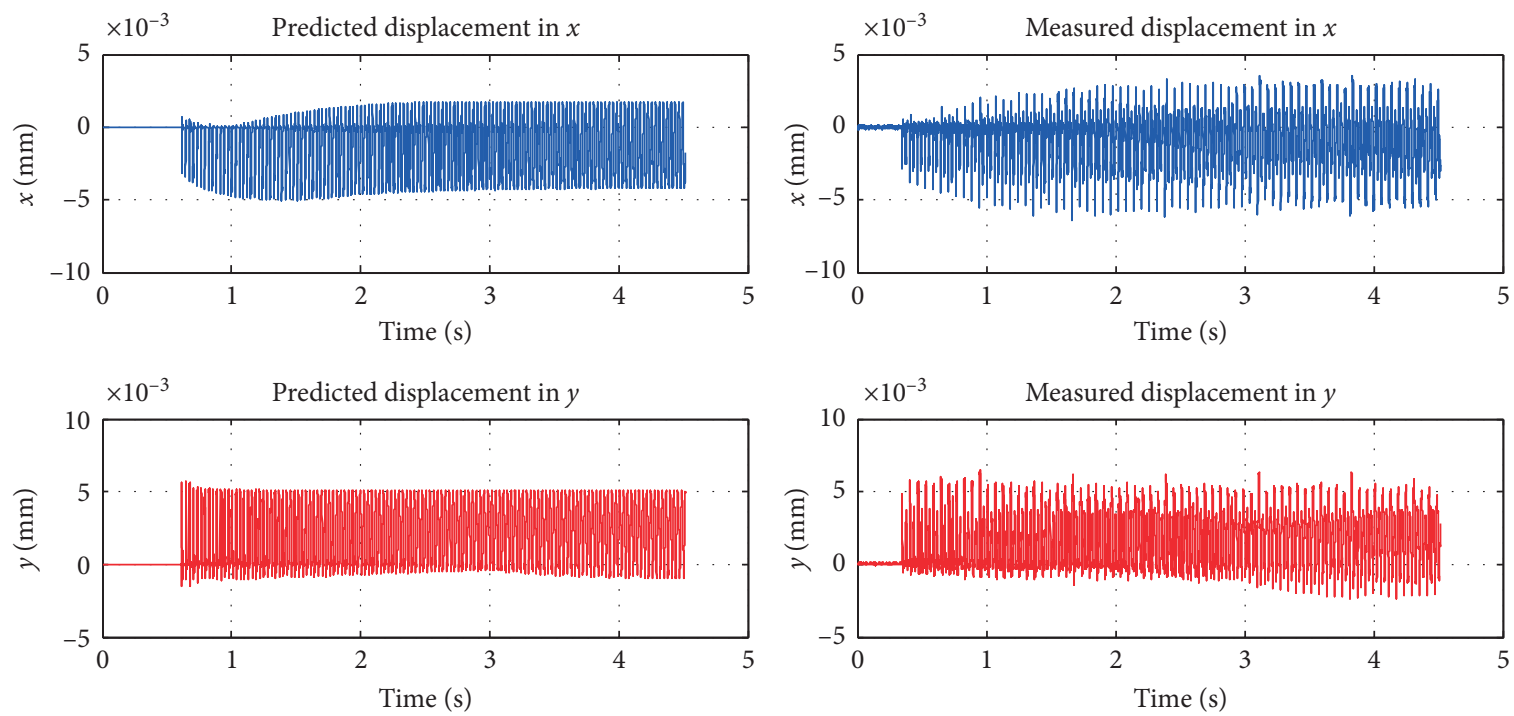

(a)
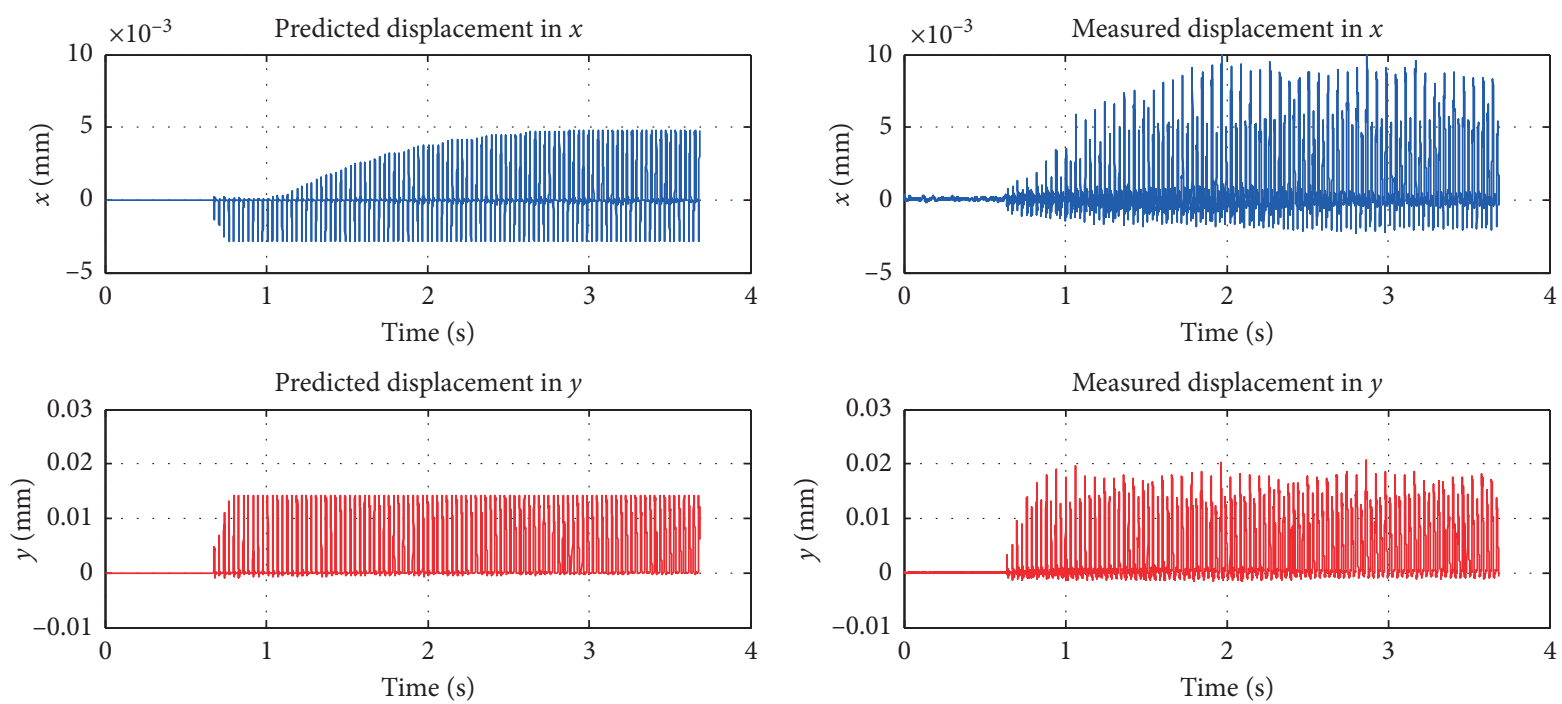

(b)
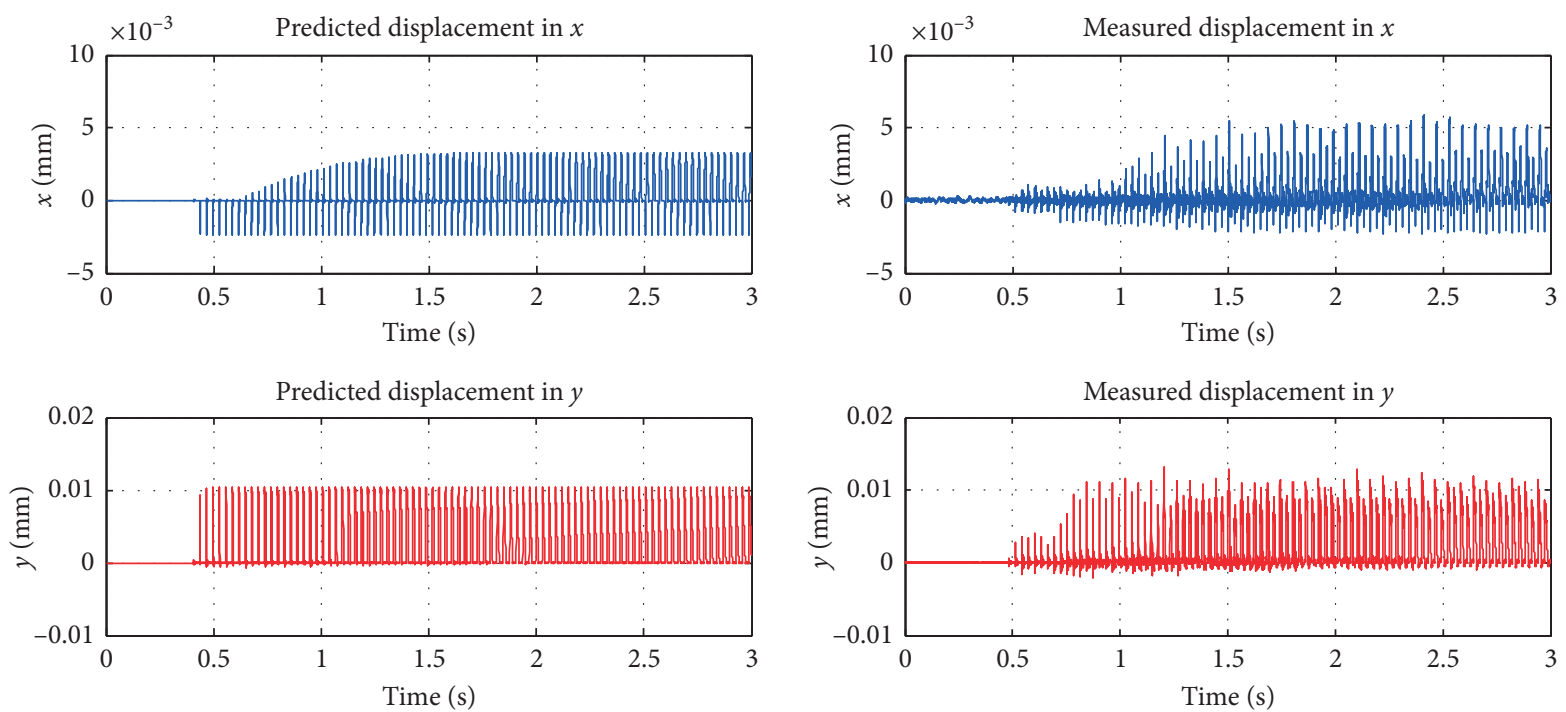

(c)

Figure 15: Continued. 

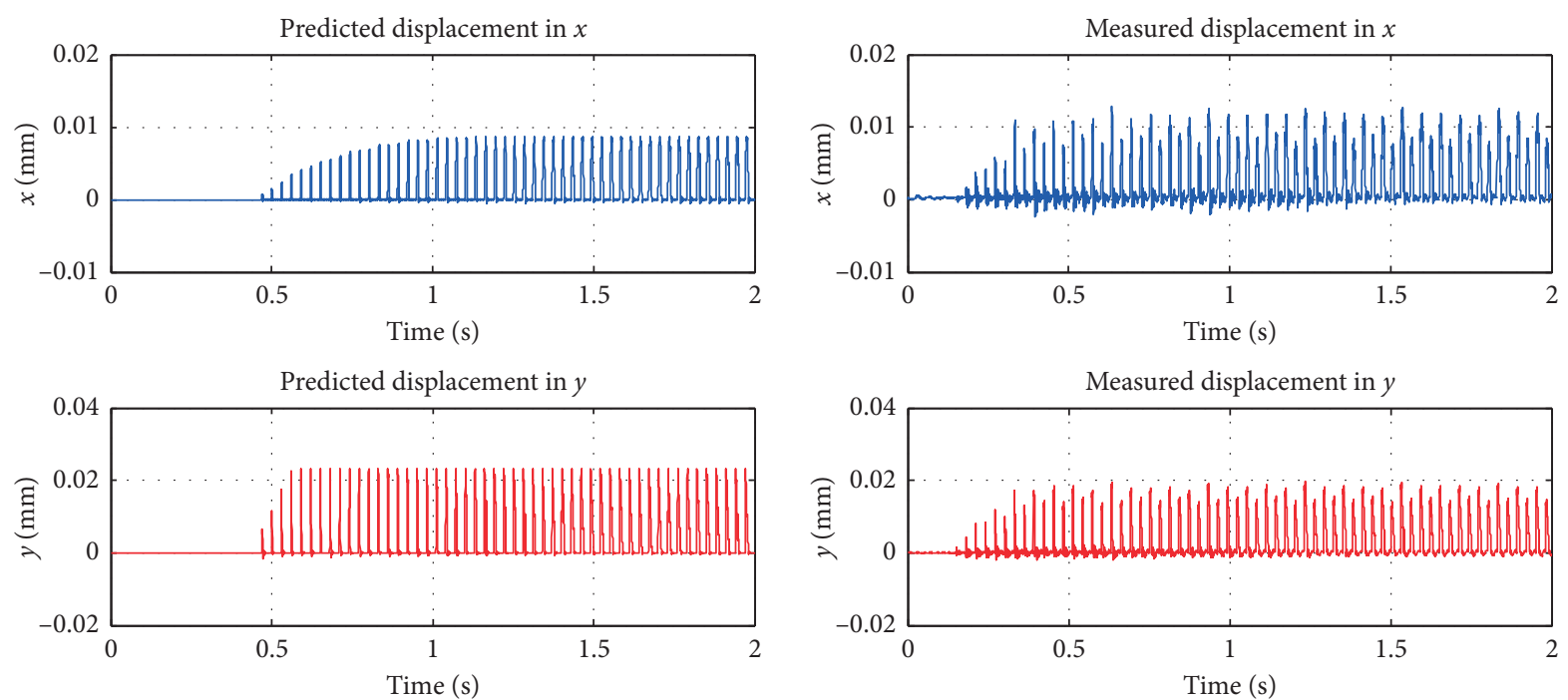

(d)

FIgURE 15: Simulated and measured cutter vibrations when the cutter entering the workpiece along a straight line: (a) Test No. 3, (b) Test No. 6, (c) Test No. 7, and (d) Test No. 8.

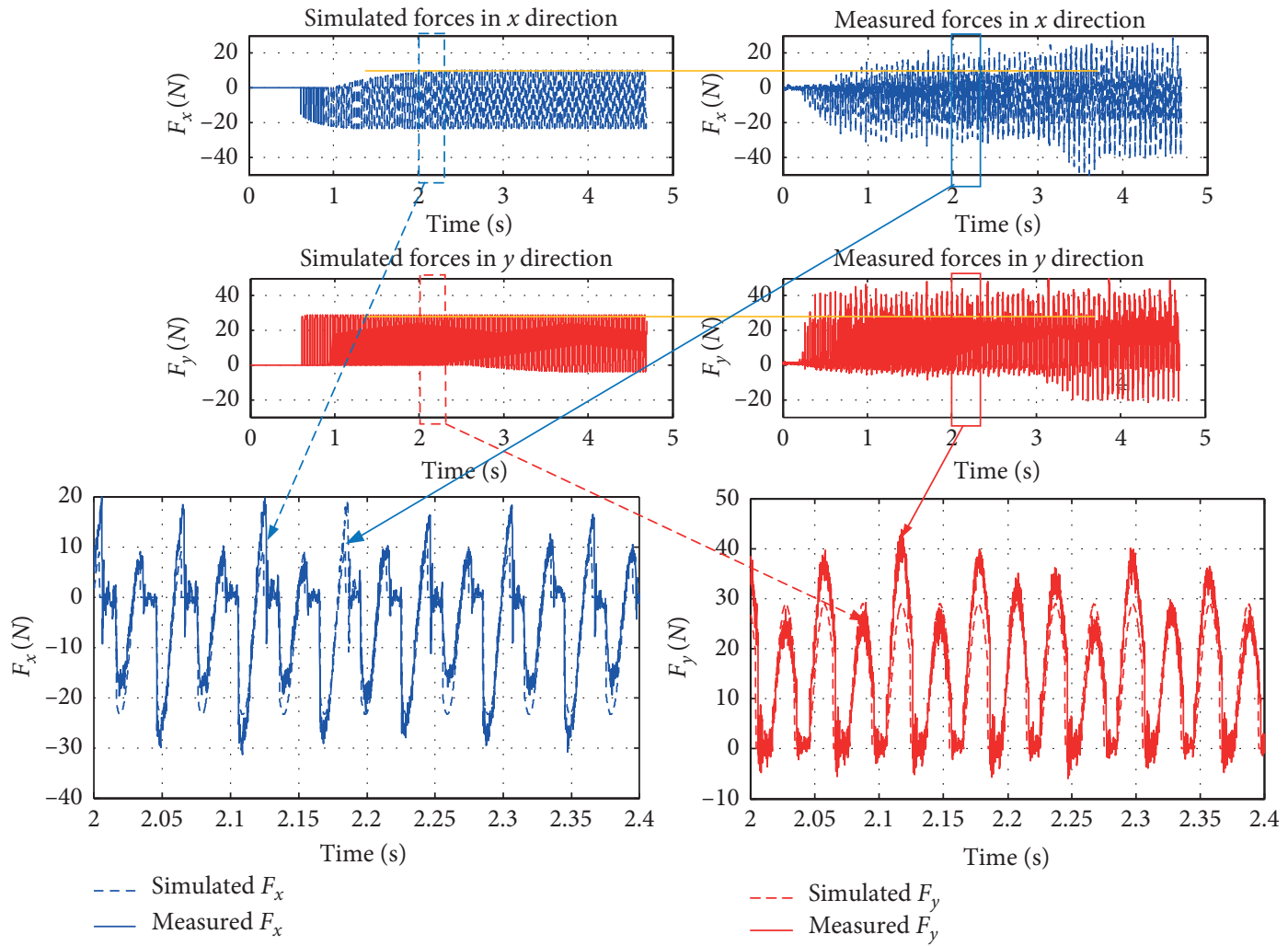

FIGURE 16: Detailed comparison of the simulation results and the experimental results.

Table 5: Simulation times for the boundary entering cases 3, 6, 7, and 8 .

\begin{tabular}{lcccc}
\hline Test No. & 3 & 6 & 7 & 8 \\
\hline Simulation time $(\mathrm{s})$ & 5.82 & 5.94 & 4.86 & 4.11 \\
\hline
\end{tabular}



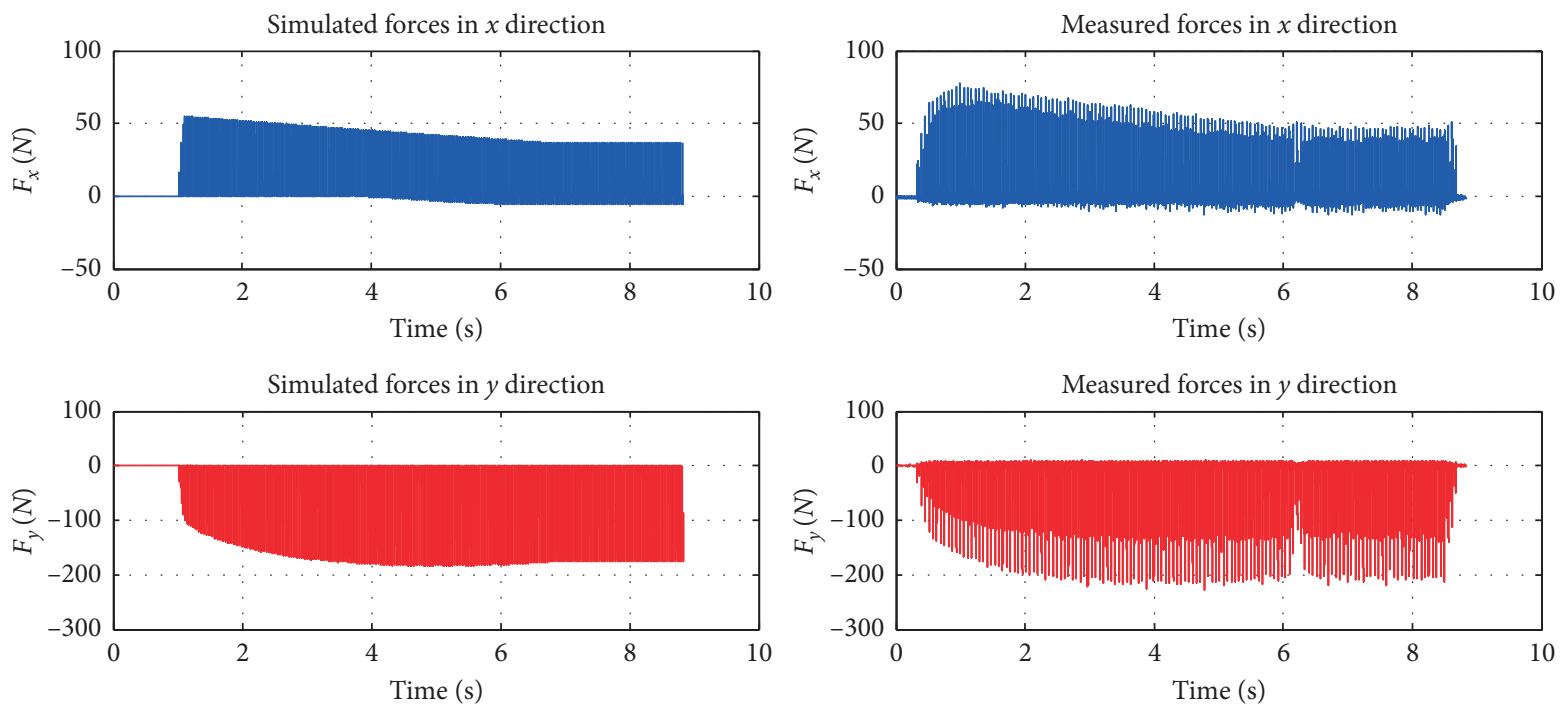

(a)
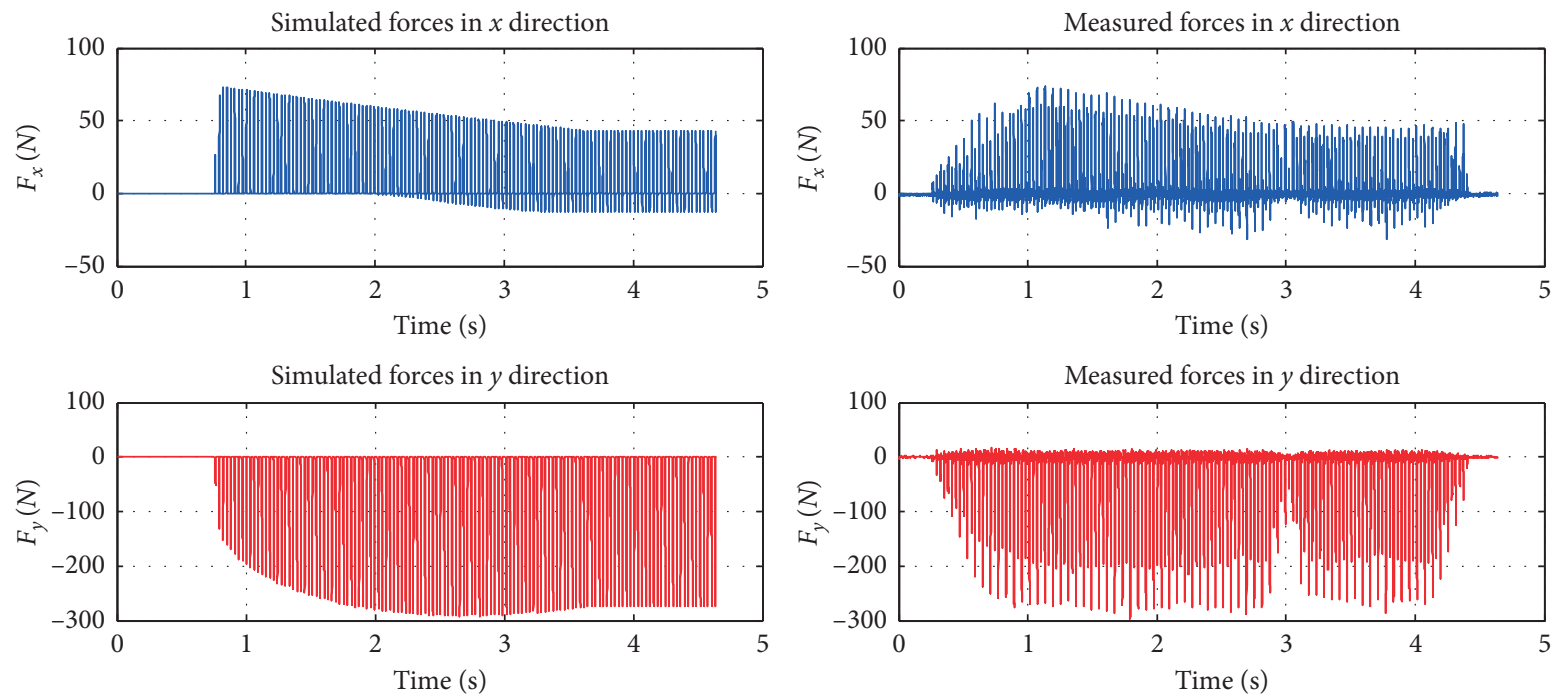

(b)
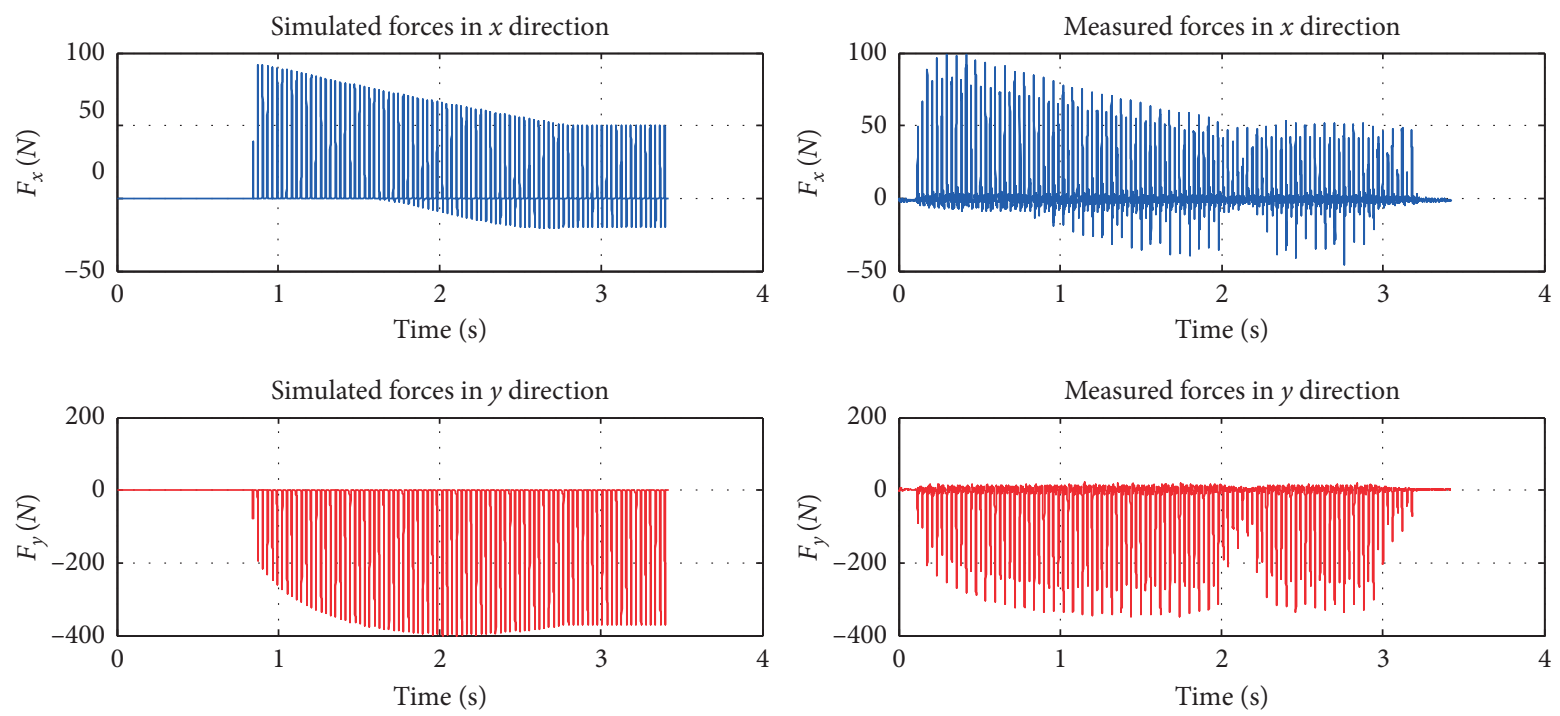

(c)

Figure 17: Continued. 

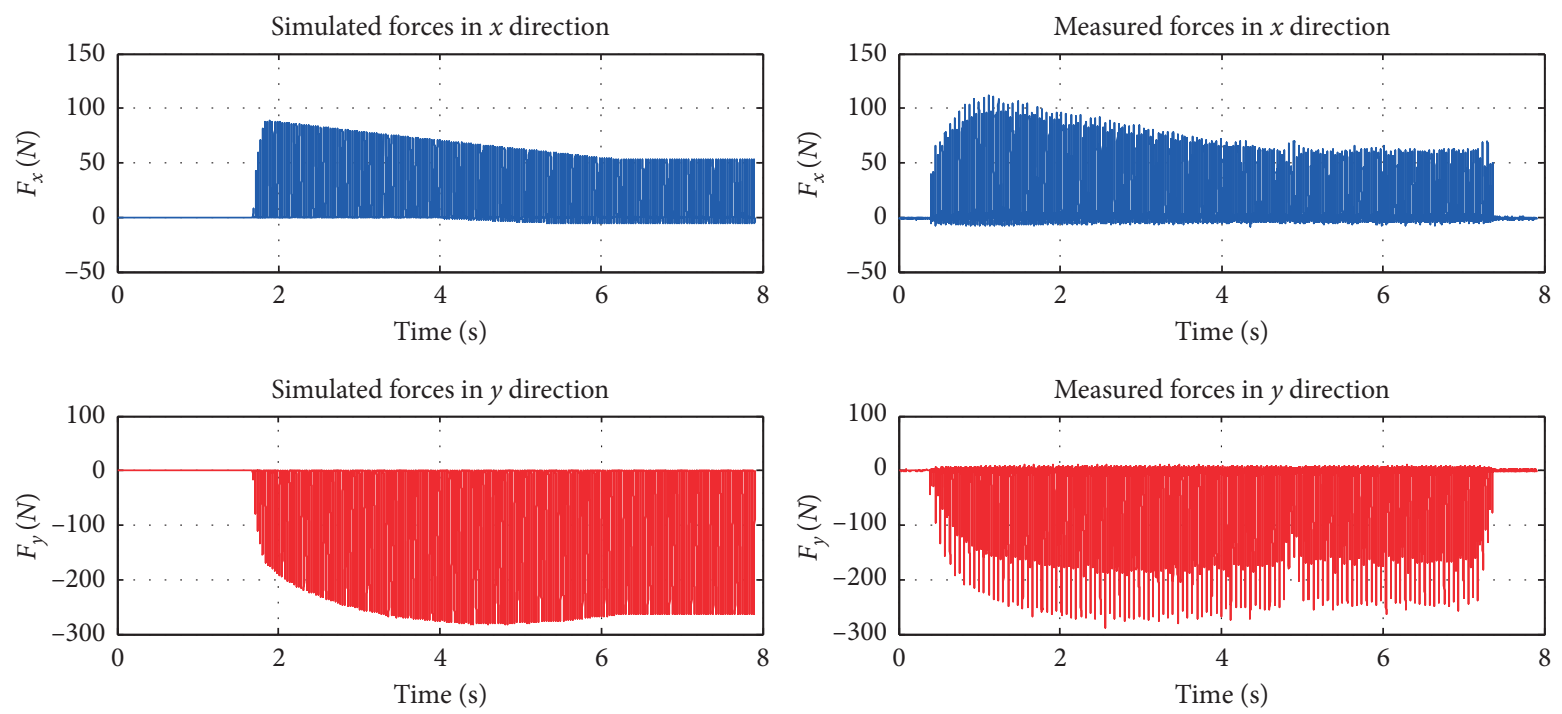

(d)
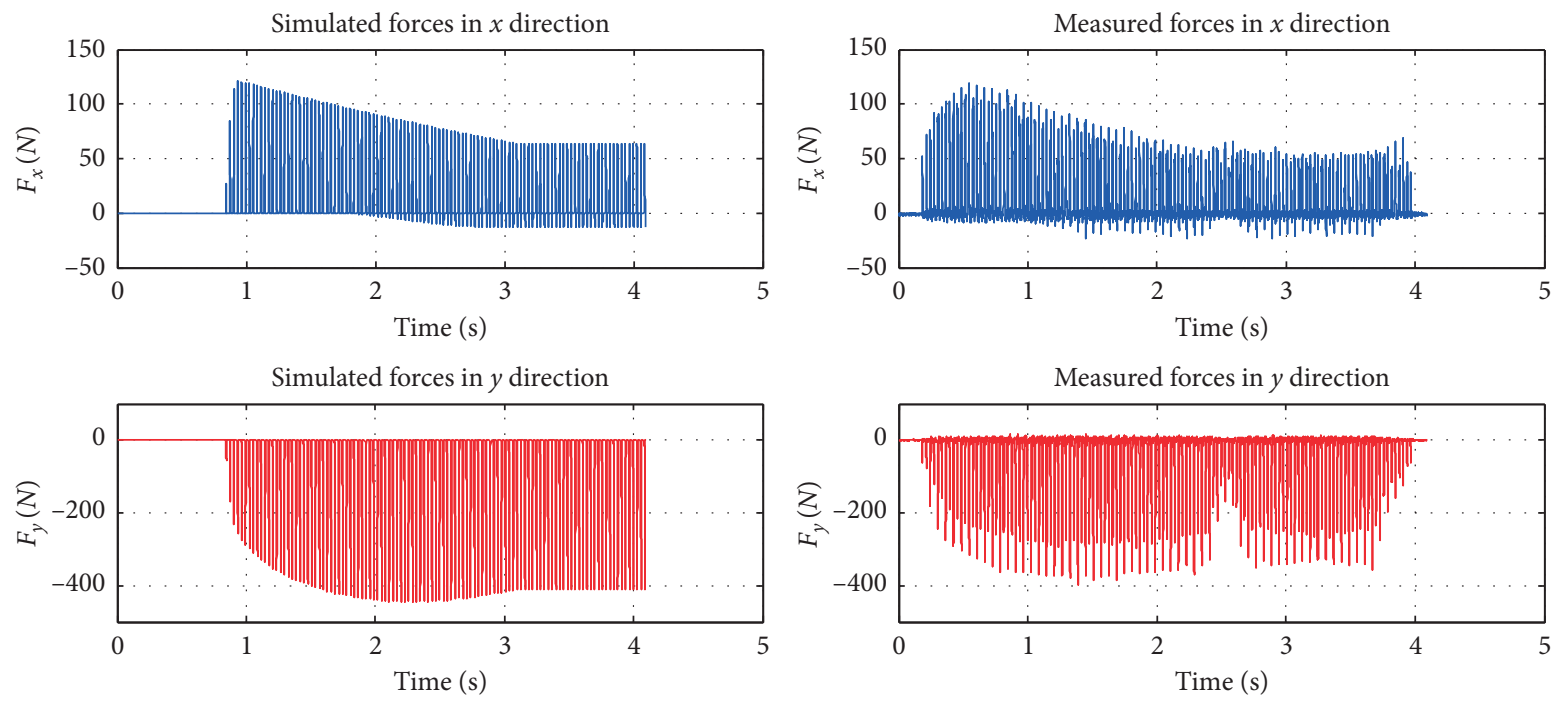

(e)
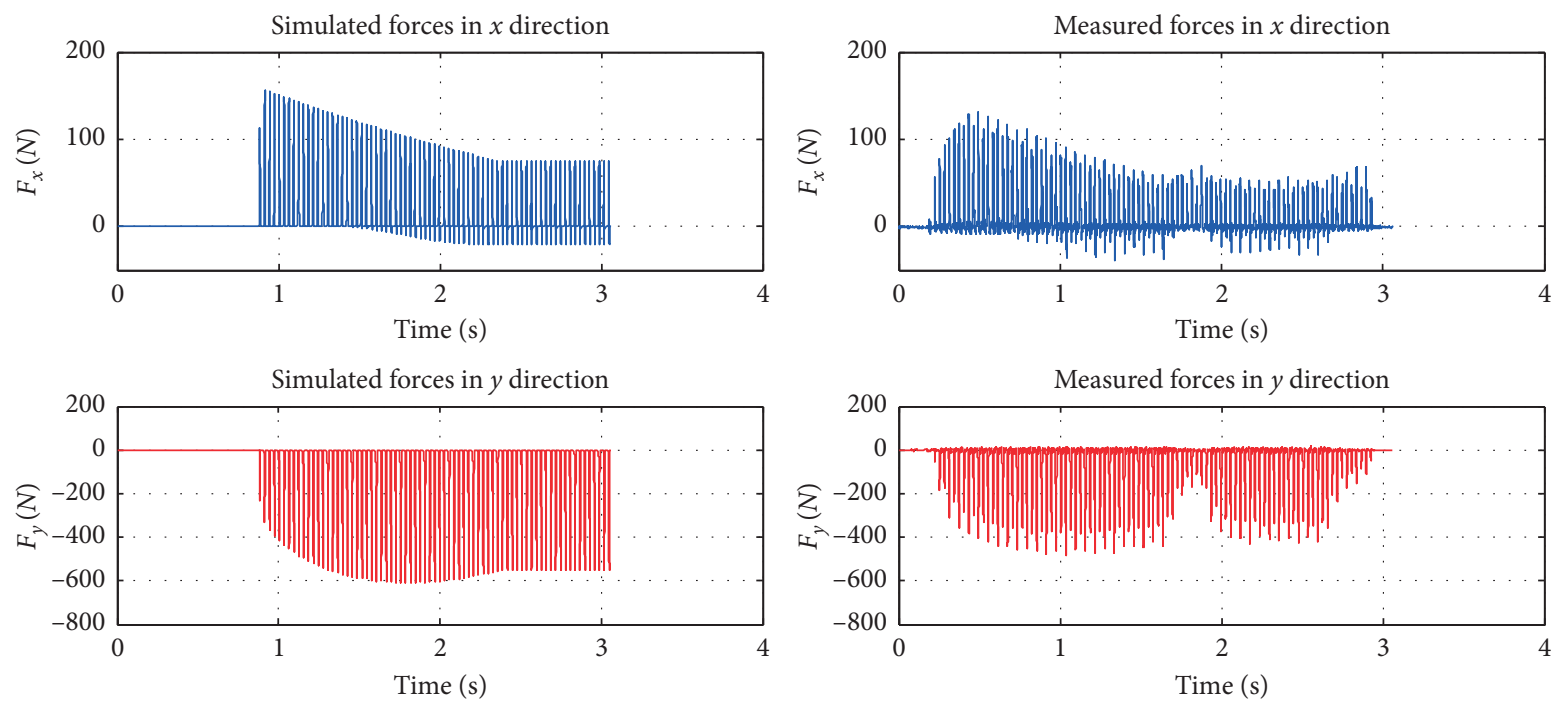

(f)

FIgURE 17: Predicted and measured forces while the cutter entering the workpiece along the cycle path: (a) Test No. 1, (b) Test No. 2, (c) Test No. 3, (d) Test No. 4, (e) Test No. 5, and (f) Test No. 6. 

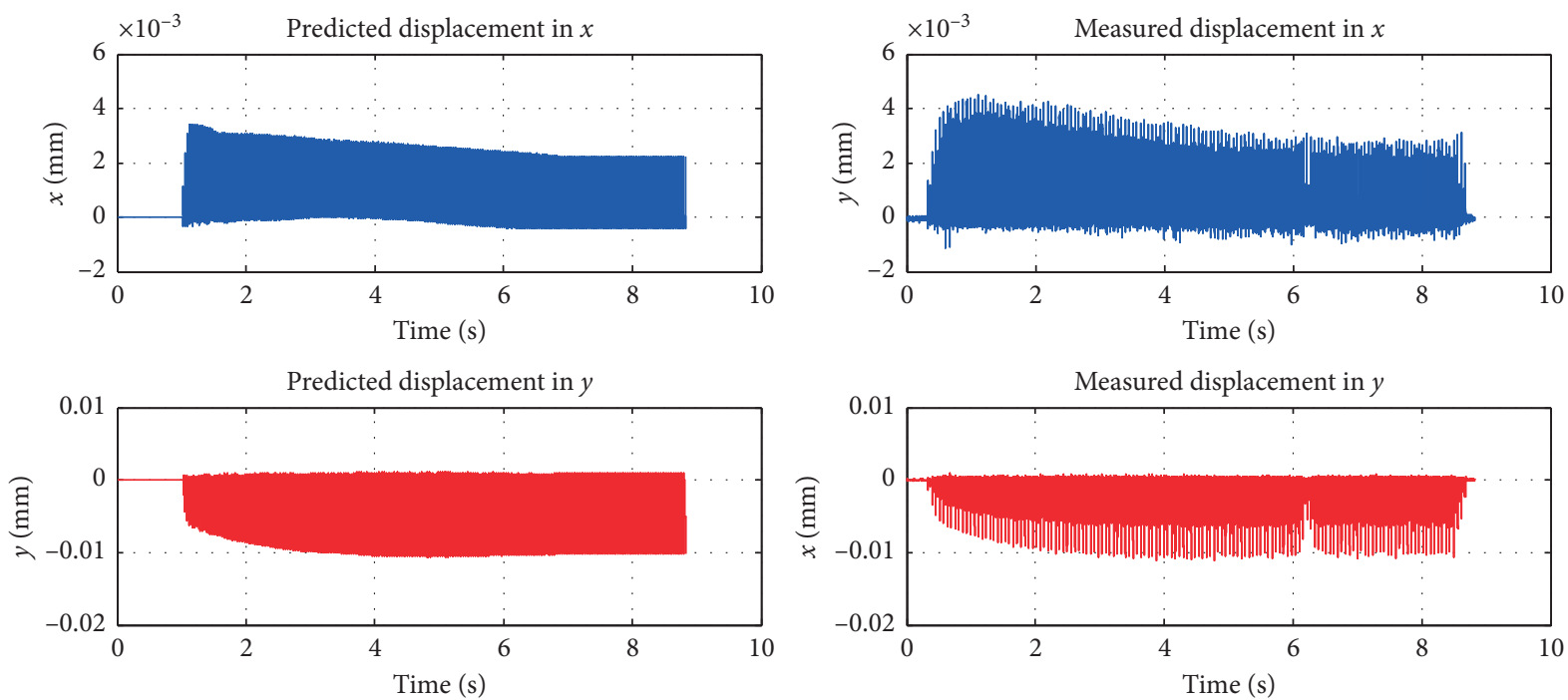

(a)
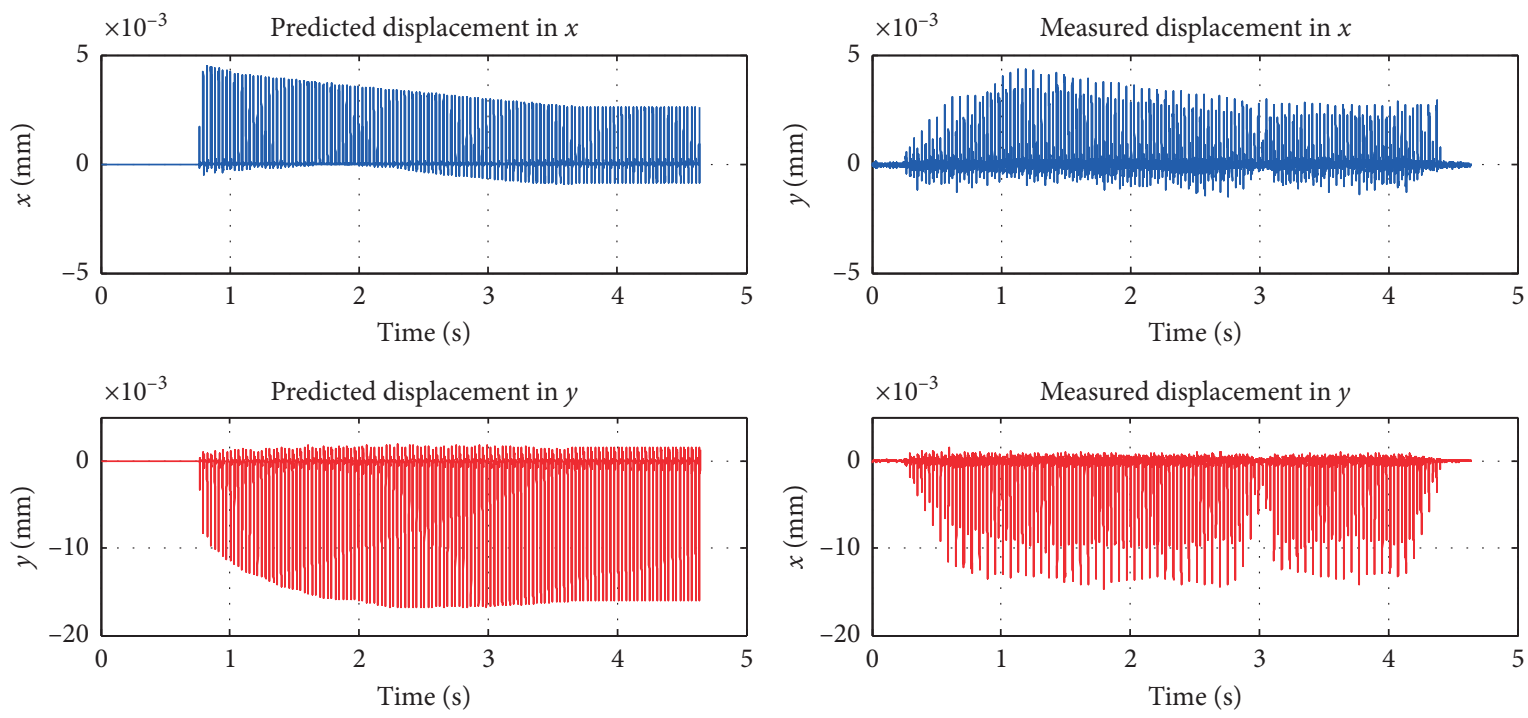

(b)
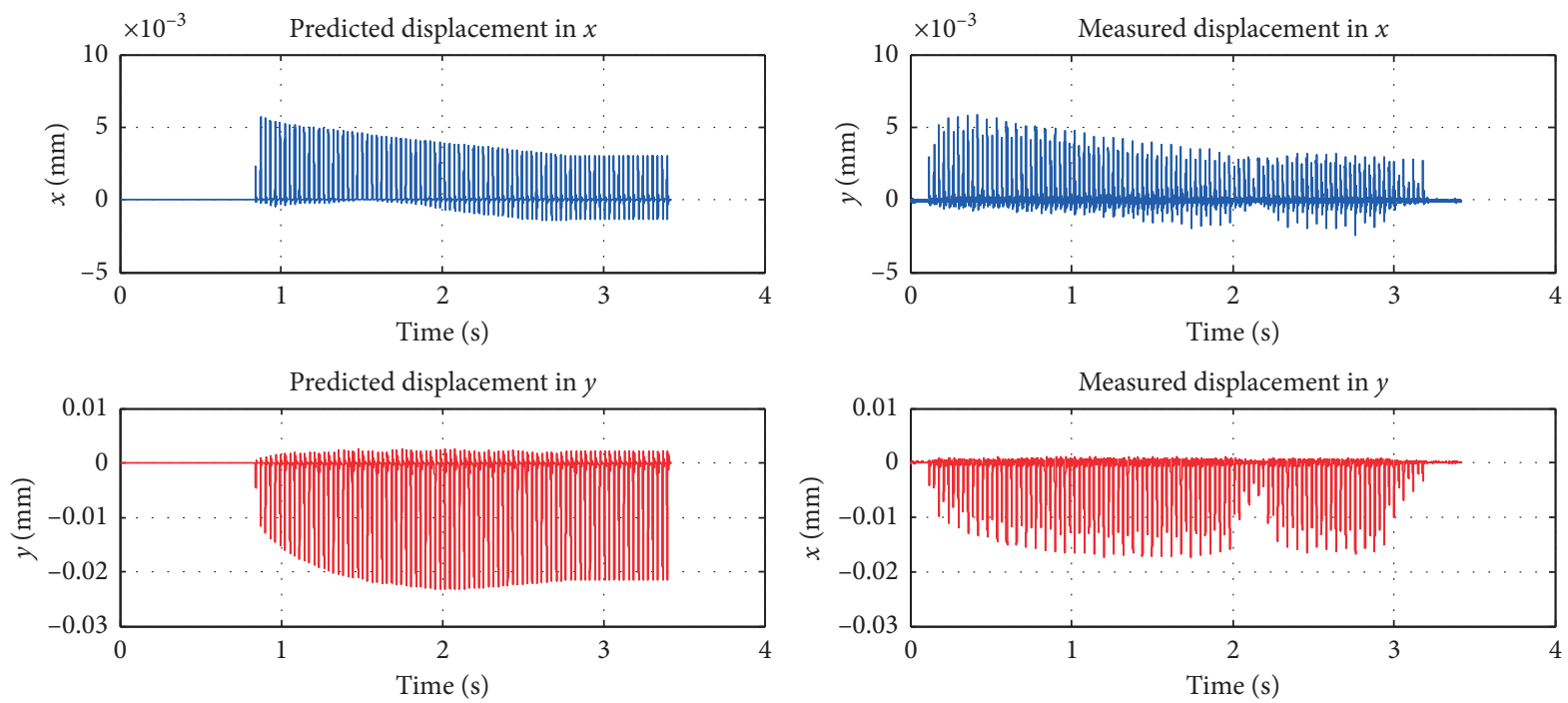

(c)

Figure 18: Continued. 

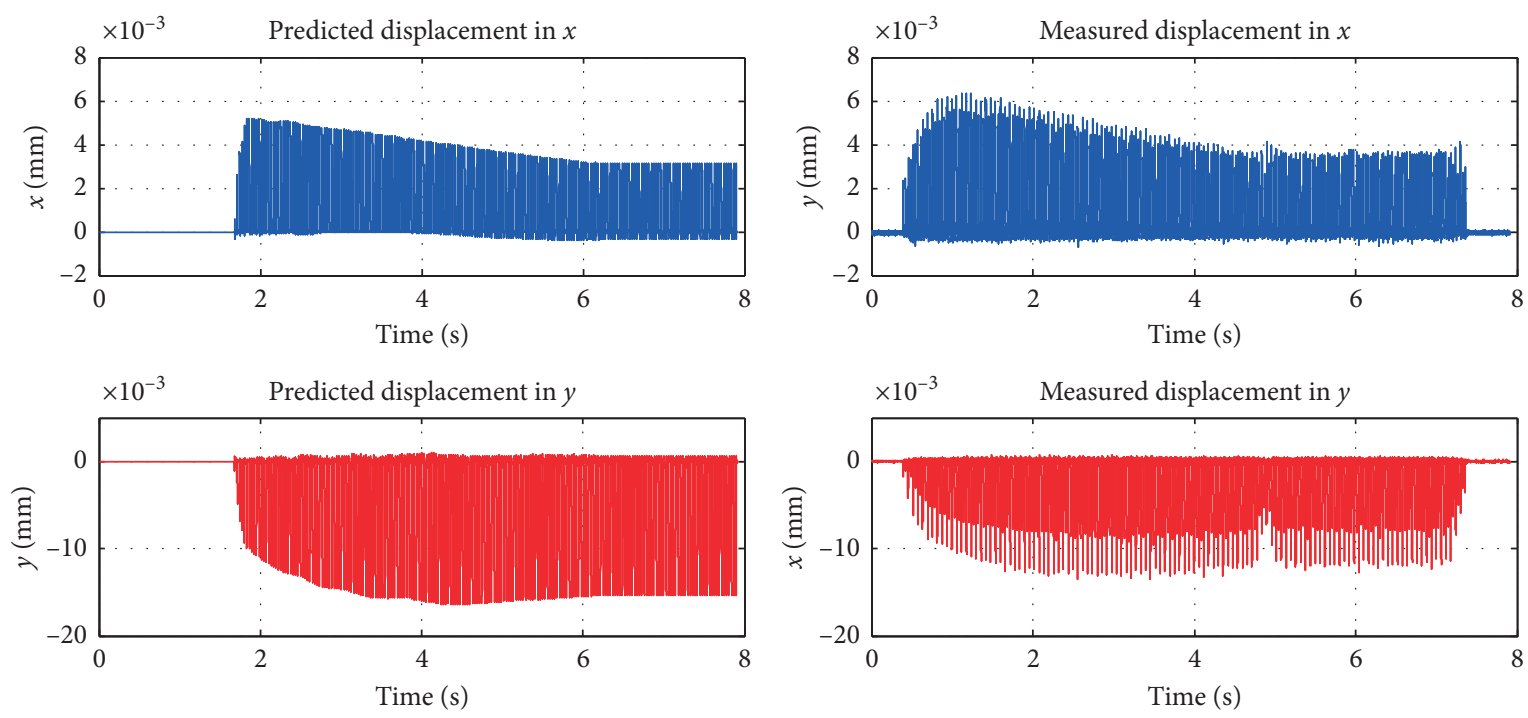

(d)
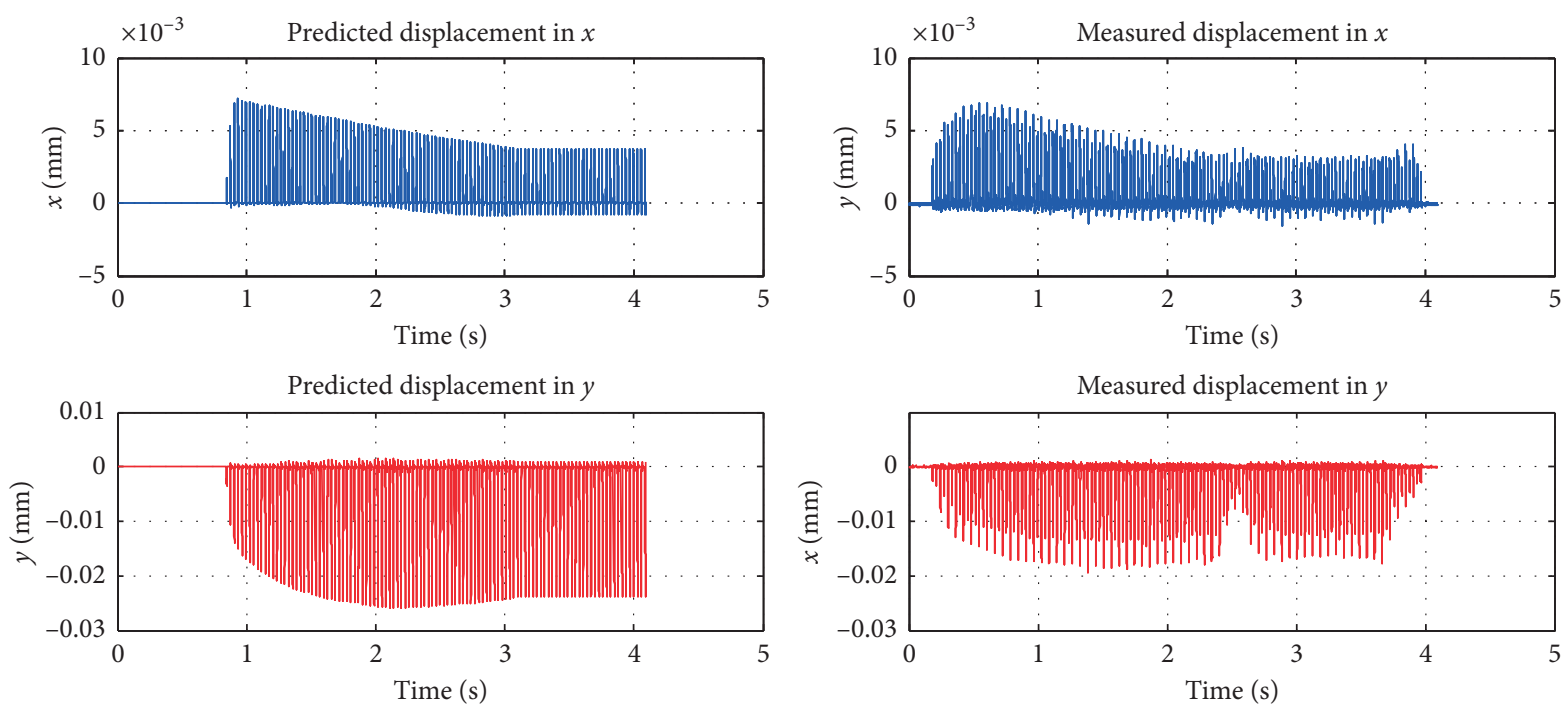

(e)
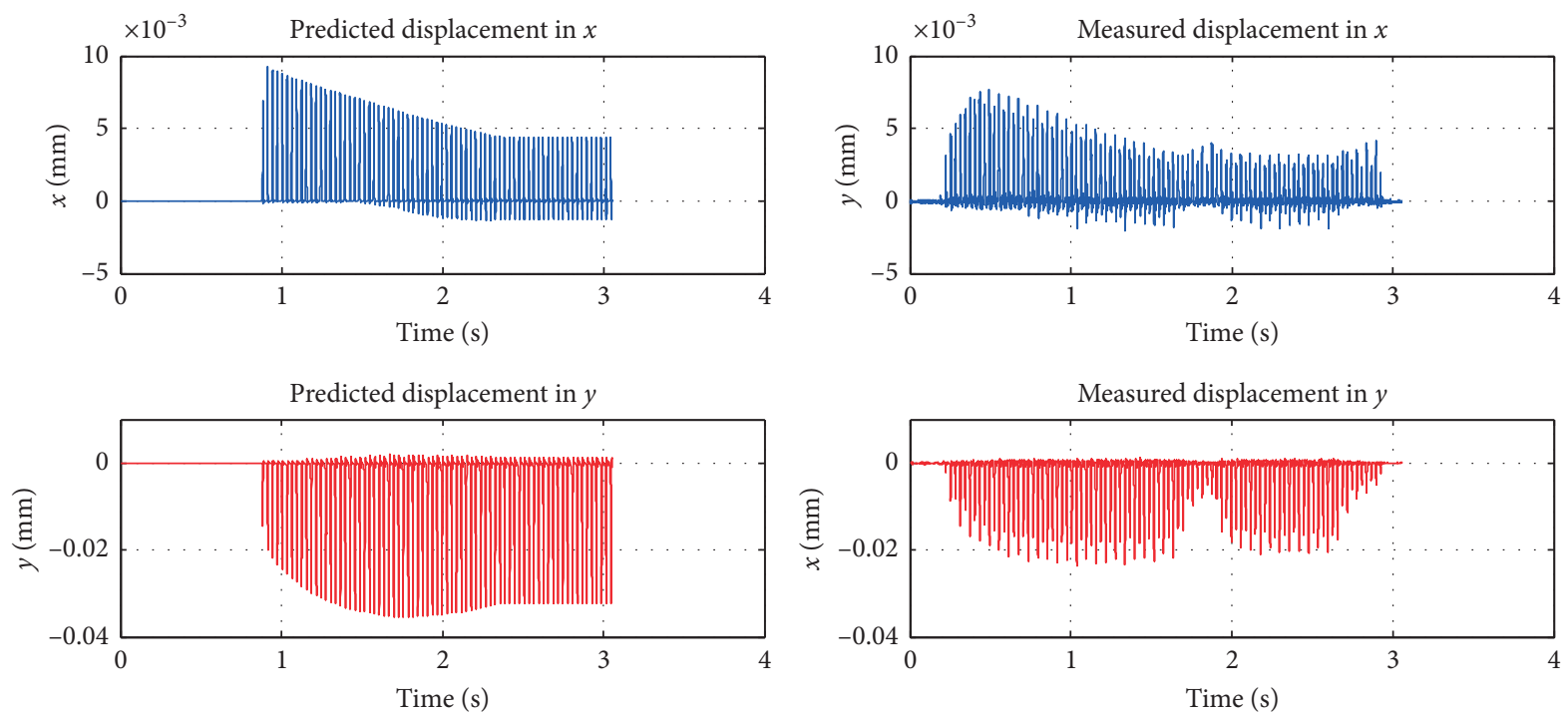

(f)

Figure 18: Predicted and measured cutter vibrations while cutter entering workpiece along the cycle path: (a) Test No. 1, (b) Test No. 2, (c) Test No. 3, (d) Test No. 4, (e) Test No. 5, and (f) Test No. 6. 
Test No. 2
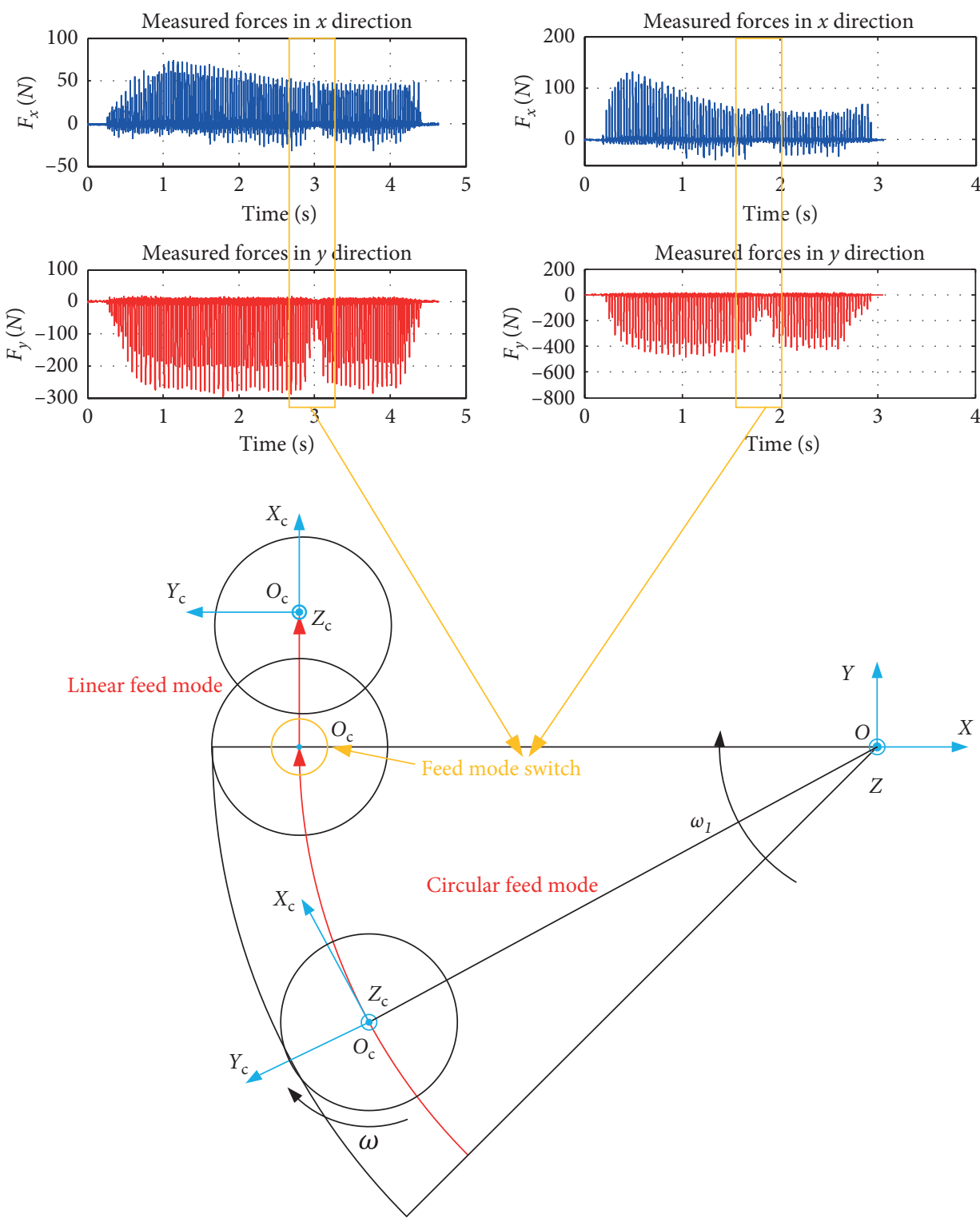

Test No. 6
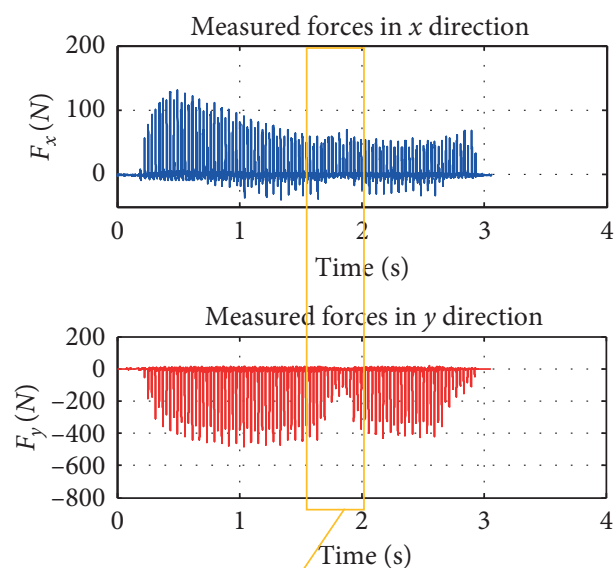

FIGURE 19: Discontinuous variation of measured forces.

TABLE 6: Cutting conditions for the measurement with cutter entering along circular paths.

\begin{tabular}{lccccc}
\hline $\begin{array}{l}\text { Test } \\
\text { No. }\end{array}$ & $\begin{array}{c}\text { Milling } \\
\text { type }\end{array}$ & Radial depth of cut $a_{\mathrm{e}}(\mathrm{mm})$ & Axial depth of cut $a_{\mathrm{p}}(\mathrm{mm})$ & $\begin{array}{c}\text { Feed per tooth } f_{\mathrm{z}} \\
(\mathrm{mm} / \text { tooth) }\end{array}$ & $\begin{array}{c}\text { Spindle speed } \\
(\mathrm{rpm})\end{array}$ \\
\hline 1 & $\mathrm{Up}$ & 1 & 2 & 0.04 & 1000 \\
2 & $\mathrm{Up}$ & 1 & 2 & 0.08 & 5 \\
$R_{1} / R$
\end{tabular}

TABLe 7: Simulation times for the circular path entering cases 1-6.

\begin{tabular}{lcccccc}
\hline Test No. & 1 & 2 & 3 & 4 & 6 & 5 \\
\hline Simulation time $(\mathrm{s})$ & 56.35 & 26.65 & 18.35 & 58.67 & 28.76 & 19.83 \\
\hline
\end{tabular}


(3) A circular path intermedium entering model of the cutter is presented by analyzing the dynamic entry angle and exit angle in the corresponding process

(4) The models have been verified by experiments under different conditions, including multiple groups of cutting parameters and two types of entering paths

On the foundation of the developed model, more conditions can be introduced to improve the model, including cutter runout, multiaxis entering, sculptured surface, and dynamic properties of low-stiffness workpieces. Furthermore, the vibration control method for the cutter entering process to maintain the machined surface integrity will be carried out.

\section{Nomenclature}

$\beta:$
$D:$
$R:$
$d z:$
$N:$
$M:$
$f:$
$f_{z}:$
$a_{\mathrm{p}}, a_{\mathrm{e}}:$
$\phi:$
$\phi_{\mathrm{p}}:$
$\psi_{i, j}(t):$
$h_{i, j}\left(\psi_{i, j}\right):$
$\Delta h_{i, j}(t):$

$K_{\mathrm{tc}}, K_{\mathrm{rc}}, K_{\mathrm{ac}}:$

$K_{\text {te }}, K_{\text {re }}, K_{\text {ae }}$ :

$F_{\mathrm{t}, i, j}(t), F_{\mathrm{r}, i, j}(t), F_{\mathrm{a}, i, j}(t)$ : Tangential force, radial force,

$F_{x, i, j}(t), F_{y, i, j}(t), F_{z, i, j}(t)$ : Cutting forces in the CCS on

$F_{x}(t), F_{y}(t), F_{z}(t)$ :

$O_{c}-X_{c} Y_{c} Z_{c}$

$\mathbf{T}\left(\psi_{i, j}(t)\right)$ :

$\mathbf{M}, \mathbf{C}, \mathbf{K}$ :

$\mathbf{a}(t), \mathbf{v}(t), \mathbf{X}(t):$

$\mathbf{F}(t)$ :

$\mathbf{D}_{\mathrm{c}}(t)$ : and axial force on the $j^{\text {th }}$ disk of $i^{\text {th }}$ tooth at $t$ the $j^{\text {th }}$ disk of $i^{\text {th }}$ tooth at $t$

Helix angle of the flank edge

Ideal cutter diameter

Ideal cutter radius

Axial thickness of one cutter

disk

Tooth number of the cutter

Number of disks on the cutter

Feed speed

Feed per tooth

Axial and radial depths of cut

Cutter rotatory angle

Pitch angle of the cutter

Angular position of the $j^{\text {th }}$ disk of $i^{\text {th }}$ tooth at $t$

Undeformed chip thickness on the $j^{\text {th }}$ disk of $i^{\text {th }}$ tooth

Variation of undeformed

chip thickness on the $j^{\text {th }}$ disk of $i^{\text {th }}$ tooth

Tangential, radial, and axial

shearing coefficients

Tangential, radial, and axial

Cutting forces in the CCS on

the whole cutter at $t$

Cutter coordinate system

(CCS)

Mass matrix, damping matrix, and stiffness matrix of the cutter

Acceleration vector, velocity vector, and displacement vector of the cutter

Driving force vector

Position of cutter at $t$
Transform matrix at $t$
$\mathbf{D}_{\mathrm{p}}(t):$

$H_{i, j}(t):$

$h_{\mathrm{s}}\left(\psi_{i, j}(t)\right), h_{\mathrm{d}}\left(\psi_{i, j}(t)\right):$

$\mathbf{f}_{\mathrm{v}}(t)$ :

$F_{\mathrm{t}, i, j}(t), F_{\mathrm{r}, i, j}(t), F_{\mathrm{a}, i, j}(t):$

$F_{x, i, j}(t), F_{y, i, j}(t), F_{z, i, j}(t)$ :

$F_{x}(t), F_{y}(t), F_{z}(t)$ :

$\phi_{\mathrm{st}}, \phi_{\mathrm{ex}}:$

$s_{1}, s_{2}, s_{3}$ :

$s_{0}$ :

S:

$s(t):$

$\phi_{\mathrm{dst}}(t), \phi_{\mathrm{dex}}(t):$

$R_{1}$ :

$H:$

$\omega:$

$\omega_{1}:$

$\theta(t):$

$\theta_{1}, \theta_{2}$ :

$\overrightarrow{\mathbf{X}_{\mathrm{c}}(t)}, \overrightarrow{\mathbf{Y}_{\mathrm{c}}(t)}, \overrightarrow{\mathbf{Z}_{\mathrm{c}}(t)}$

$\overrightarrow{\mathbf{O}_{\mathrm{c}}(t)}$ :

$x\left(t_{k}\right), x\left(t_{k+1}\right):$

$x_{1}\left(t_{k}\right), x_{1}\left(t_{k+1}\right):$

$K_{1}, K_{2}, K_{3}, K_{4}$

$L_{1}, L_{2}, L_{3}, L_{4}$ :
Position of the cutter while the cutter was in contact with workpiece before $t$, and the time interval is integral multiple for the cutter to rotate one pitch angle

The dynamic undeformed chip thickness on the $j^{\text {th }}$ disk of $i^{\text {th }}$ tooth at $t$

Static UCT and dynamic UCT on the $j^{\text {th }}$ disk of $i^{\text {th }}$ tooth at $t$ Additional feed caused by cutter vibration at $t$

Tangential force, radial force, and axial force on the $j^{\text {th }}$ disk of $i^{\text {th }}$ tooth at $t$

: Cutting forces in the CCS on the $j^{\text {th }}$ disk of $i^{\text {th }}$ tooth at $t$ Cutting forces in the CCS on the whole cutter at $t$ Immersion angle and exit angle Three critical positions of the cutter in the entering process from workpiece boundary Distance between starting point and boundary of workpiece The total distance of cutter movement in the entering process from workpiece boundary

Position of the cutter at $t$ Time-varied immersion angle and exit angle at $t$

Radius of the circular path radius to the cutter radius Angular speed of the cutter Angular speed of the cutter moving along the circular path Angular position of the cutter on the circular path cutter entering the workpiece Direction vectors of the $x$-axis, $y$-axis, and $z$-axis in CCS Position vector of the original point in CCS

Displacement of the cutter at $t_{k}$ and $t_{k+1}$ Velocity of the cutter at $t_{k}$ and $t_{k+1}$

Intermediate parameters in the Runge-Kutta method. Multiple of the circular path Critical angular positions of the

\section{Data Availability}

The data used to support the findings of this study are available from the corresponding author upon request. 


\section{Conflicts of Interest}

The authors declare that they have no conflicts of interest.

\section{Acknowledgments}

This study was cosupported by the National Natural Science Foundation of China (No. 51675438), the Fundamental Research Funds for the Central Universities (Nos. 3102017gx06008 and 3102018jcc004), and the 111 Project of China (No. B13044).

\section{References}

[1] M. Luo, C. Han, and H. M. Hafeez, "Four-axis trochoidal toolpath planning for rough milling of aero-engine blisks," Chinese Journal of Aeronautics, 2018, In press.

[2] R. M'Saoubi, D. Axinte, S. L. Soo et al., "High performance cutting of advanced aerospace alloys and composite materials," CIRP Annals-Manufacturing Technology, vol. 64, no. 2, pp. 557-580, 2015.

[3] W. Ding, C. Dai, T. Yu, J. Xu, and Y. Fu, "Grinding performance of textured monolayer CBN wheels: undeformed chip thickness nonuniformity modeling and ground surface topography prediction," International Journal of Machine Tools and Manufacture, vol. 122, pp. 66-80, 2017.

[4] Q. Yao, M. Luo, D. Zhang, and B. Wu, "Identification of cutting force coefficients in machining process considering cutter vibration," Mechanical Systems and Signal Processing, vol. 103, pp. 39-59, 2018.

[5] M. Luo, H. Luo, D. Zhang, and K. Tang, "Improving tool life in multi-axis milling of Ni-based superalloy with ball-end cutter based on the active cutting edge shift strategy," Journal of Materials Processing Technology, vol. 252, pp. 105-115, 2018.

[6] X.-B. Dang, M. Wan, Y. Yang, and W.-H. Zhang, "Efficient prediction of varying dynamic characteristics in thin-wall milling using freedom and mode reduction methods," International Journal of Mechanical Sciences, vol. 150, pp. 202-216, 2019.

[7] Q. Song, G. Ju, Z. Liu, and X. Ai, "Subdivision of chatter-free regions and optimal cutting parameters based on vibration frequencies for peripheral milling process," International Journal of Mechanical Sciences, vol. 83, pp. 172-183, 2014.

[8] K. Cheng, Machining Dynamics: Fundamentals, Applications and Practices, Springer, Berlin, Germany, 2009.

[9] Y. Altintas, Manufacturing Automation: Metal Cutting Mechanics, Machine Tool Vibration, and CNC Design, Cambridge University Press, Cambridge, UK, 2nd edition, 2012.

[10] M. Luo, H. Luo, D. Axinte, D. Liu, J. Mei, and Z. Liao, "A wireless instrumented milling cutter system with embedded PVDF sensors," Mechanical Systems and Signal Processing, vol. 110, pp. 556-568, 2018.

[11] Q. Song, J. Shi, Z. Liu, Y. Wan, and F. Xia, "Boring bar with constrained layer damper for improving process stability," International Journal of Advanced Manufacturing Technology, vol. 83, no. 9, pp. 1951-1966, 2016.

[12] F. Taylor, On the Art of Cutting Metals, American Society of Mechanical Engineers, New York, NY, USA, 1907.

[13] Y. Altintas and E. Budak, "Analytical prediction of stability lobes in milling," Annals of the CIRP, vol. 44, no. 1, pp. 357-362, 1995.

[14] T. Insperger and G. Stépán, "Semi-discretization method for delayed systems," International Journal for Numerical Methods in Engineering, vol. 55, no. 5, pp. 503-518, 2002.

[15] Y. Ding, L. Zhu, X. Zhang, and H. Ding, "Numerical integration method for prediction of milling stability," Journal of Manufacturing Science and Engineering, vol. 133, no. 3, pp. 031005-031009, 2011.

[16] Y. Lu, Y. Ding, and L. Zhu, "Dynamics and stability prediction of five-axis flat-end milling," Journal of Manufacturing Science and Engineering, vol. 139, no. 6, pp. 061015-061011, 2017.

[17] M. Wan, Y.-C. Ma, J. Feng, and W.-H. Zhang, "Study of static and dynamic ploughing mechanisms by establishing generalized model with static milling forces," International Journal of Mechanical Sciences, vol. 114, pp. 120-131, 2016.

[18] Y. Sun and S. Jiang, "Predictive modeling of chatter stability considering force-induced deformation effect in milling thinwalled parts," International Journal of Machine Tools and Manufacture, vol. 135, pp. 38-52, 2018.

[19] C. Liu, L. Zhu, and C. Ni, "Chatter detection in milling process based on VMD and energy entropy," Mechanical Systems and Signal Processing, vol. 105, pp. 169-182, 2018.

[20] R. Zhu, S. G. Kapoor, and R. E. DeVor, "Mechanistic modeling of the ball end milling process for multi-axis machining of free-form surfaces," Journal of Manufacturing Science and Engineering, vol. 123, no. 3, pp. 369-379, 2001.

[21] Z.-L. Li, X.-Z. Wang, and L.-M. Zhu, "Arc-surface intersection method to calculate cutter-workpiece engagements for generic cutter in five-axis milling," Computer-Aided Design, vol. 73, pp. 1-10, 2016.

[22] Z.-L. Li and L.-M. Zhu, "An accurate method for determining cutter-workpiece engagements in five-axis milling with a general tool considering cutter runout," Journal of Manufacturing Science and Engineering, vol. 140, no. 2, pp. 021001-021011, 2018.

[23] X. Zhang, J. Zhang, B. Pang, and W. Zhao, "An accurate prediction method of cutting forces in 5-axis flank milling of sculptured surface," International Journal of Machine Tools and Manufacture, vol. 104, pp. 26-36, 2016.

[24] X. Zhang, A. Senthil Kumar, M. Rahman, C. Nath, and K. Liu, "An analytical force model for orthogonal elliptical vibration cutting technique," Journal of Manufacturing Processes, vol. 14, no. 3, pp. 378-387, 2012.

[25] M. L. Campomanes and Y. Altintas, "An improved time domain simulation for dynamic milling at small radial immersions," Journal of Manufacturing Science and Engineering, vol. 125, no. 3, pp. 416-422, 2003.

[26] H. Li and Y. C. Shin, "A comprehensive dynamic end milling simulation model," Journal of Manufacturing Science and Engineering, vol. 128, no. 1, pp. 86-95, 2005.

[27] M. Luo, J. Mei, and D. Zhang, "Time-domain modeling of a cutter exiting a workpiece in the slot milling process," Chinese Journal of Aeronautics, vol. 29, no. 6, pp. 1852-1858, 2016.

[28] S. B. Wang, L. Geng, Y. F. Zhang, K. Liu, and T. E. Ng, "Cutting force prediction for five-axis ball-end milling considering cutter vibrations and run-out," International Journal of Mechanical Sciences, vol. 96-97, pp. 206-215, 2015.

[29] J. C. Butcher, The Numerical Analysis of Ordinary Differential Equations: Runge-Kutta and General Linear Methods, WileyInterscience, Hoboken, NJ, USA, 1987.

[30] M. Wan, W.-H. Zhang, J.-W. Dang, and Y. Yang, "A novel cutting force modelling method for cylindrical end mill," Applied Mathematical Modelling, vol. 34, no. 3, pp. 823-836, 2010. 


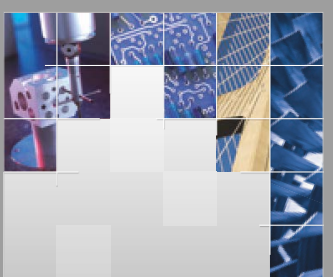

\section{Enfincering}
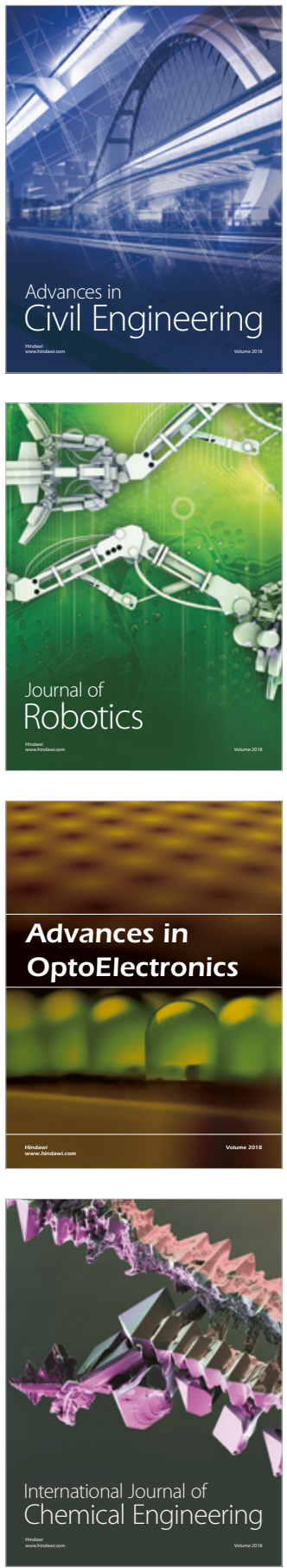

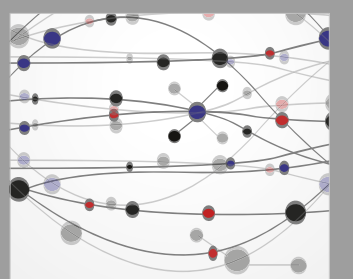

\section{Rotating \\ Machinery}

The Scientific World Journal

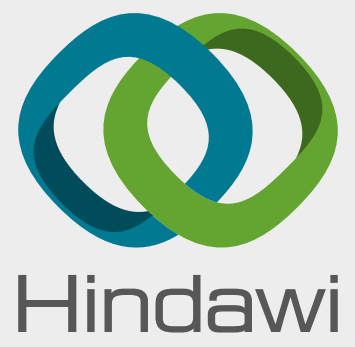

Submit your manuscripts at

www.hindawi.com
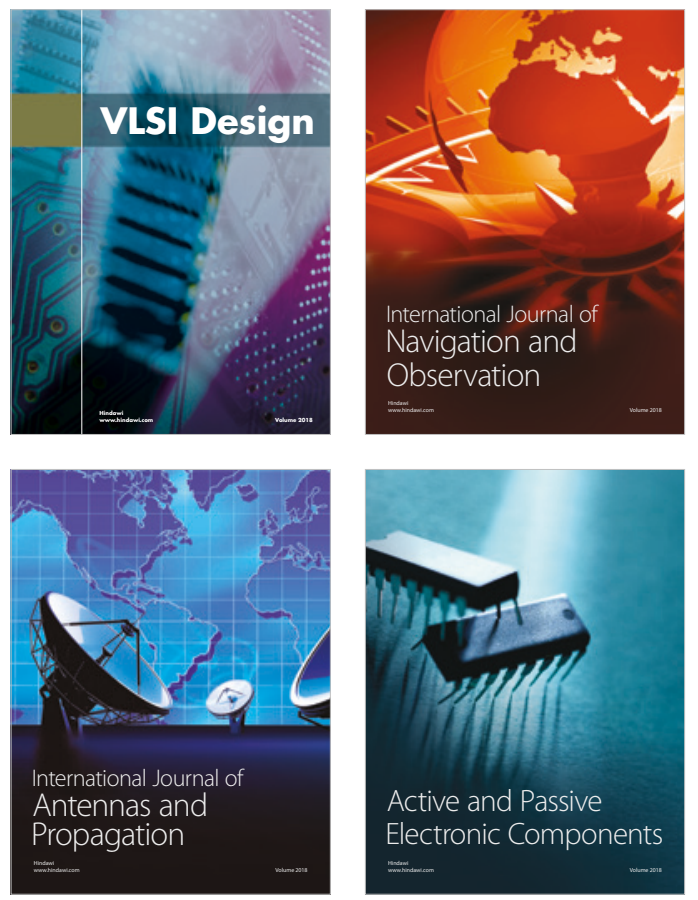
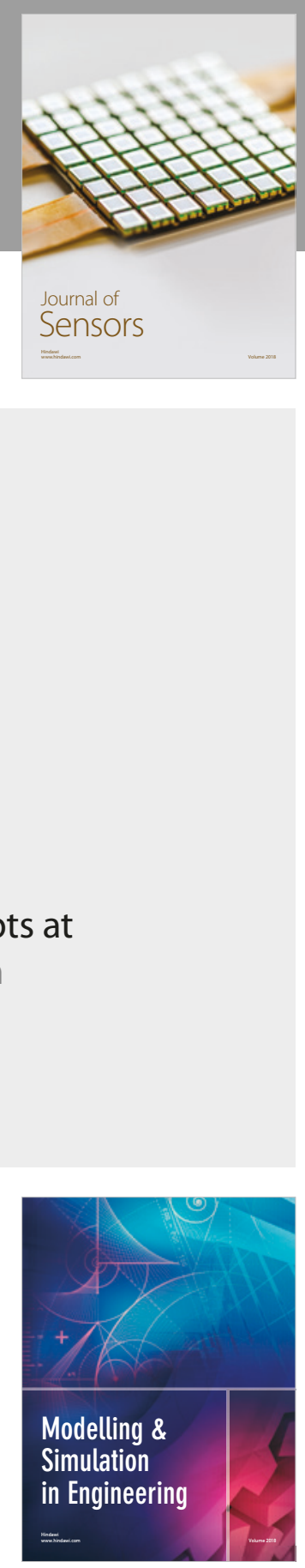

\section{Advances \\ Multimedia}
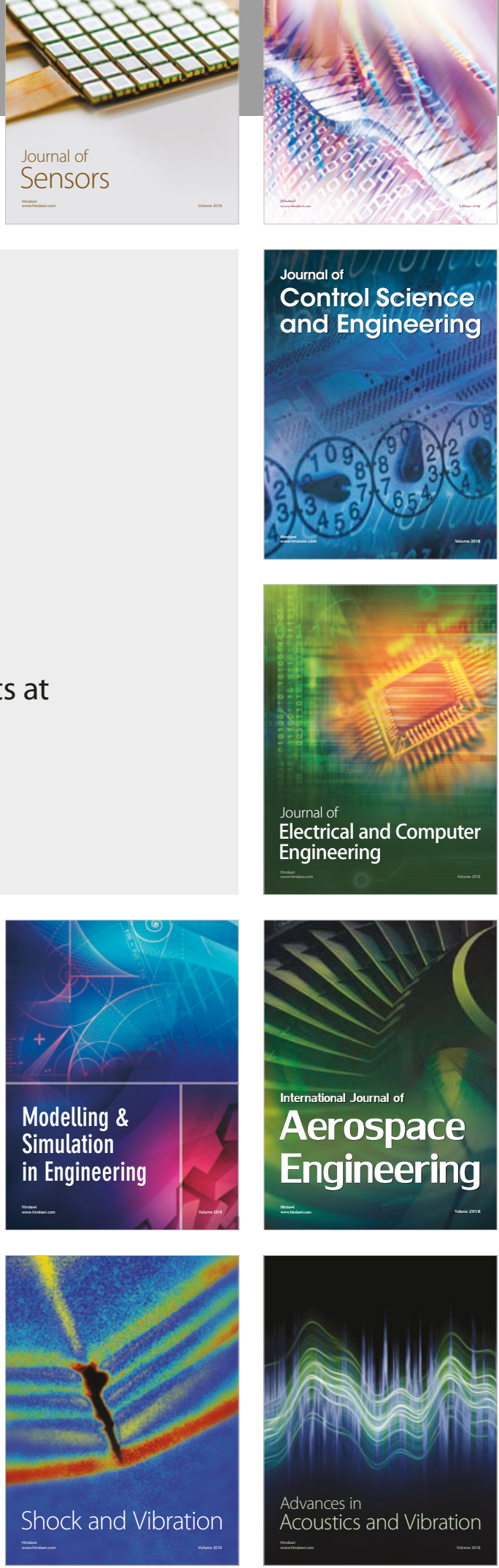